FEDERAL RESERVE BANK OF SAN FRANCISCO

WORKING PAPER SERIES

\title{
Financial Frictions, the Housing Market, and Unemployment
}

\author{
William A. Branch \\ University of California Irvine \\ Nicolas Petrosky-Nadeau \\ Federal Reserve Bank of San Francisco \\ and Carnegie Mellon University \\ Guillaume Rocheteau \\ University of California Irvine
}

November 2014

Working Paper 2014-26

http://www.frbsf.org/economic-research/publications/working-papers/wp2014-26.pdf

The views in this paper are solely the responsibility of the authors and should not be interpreted as reflecting the views of the Federal Reserve Bank of San Francisco or the Board of Governors of the Federal Reserve System. 


\title{
Financial Frictions, the Housing Market, and Unemployment.*
}

\author{
William A. Branch \\ University of California - Irvine
}

\author{
Nicolas Petrosky-Nadeau \\ Federal Reserve Bank of San Francisco \\ and Carnegie Mellon University
}

\section{Guillaume Rocheteau}

University of California - Irvine

First draft: March 2013

This version: November 2014

\begin{abstract}
We develop a two-sector search-matching model of the labor market with imperfect mobility of workers, augmented to incorporate a housing market and a frictional goods market. Homeowners use home equity as collateral to finance idiosyncratic consumption opportunities. A financial innovation that raises the acceptability of homes as collateral raises house prices and reduces unemployment. It also triggers a reallocation of workers, with the direction of the change depending on firms' market power in the goods market. A calibrated version of the model under adaptive learning can account for house prices, sectoral labor flows, and unemployment rate changes over 1996-2010.
\end{abstract}

JEL Classification: D82, D83, E40, E50

Keywords: credit, unemployment, limited commitment, liquidity.

*This paper has benefited from useful discussions with Aleksander Berentsen, Allen Head, and Murat Tasci. We also thank for their comments seminar participants at the Bank of Canada, at the universities of Basel, Bern, California at Irvine, Hawaii at Manoa, Carleton the 2012 cycles, adjustment, and policy conference on credit, unemployment, supply and demand, and frictions, and the 2014 Workshop on Expectations in Dynamic Macroeconomics at the Bank of Finland. These views are those of the authors and do not necessarily reflect the views of the Federal Reserve System. 


\section{Introduction}

The Mortensen and Pissarides (1994) model of equilibrium unemployment captures several frictions that plague labor markets, including imperfect competition, costly search, and matching frictions. Yet, it abstracts from financial frictions and borrowing constraints that provide powerful linkages between key markets of the macroeconomy, namely housing, goods, and labor markets. These linkages seem to have played an important role in the emergence of a housing boom/bust cycle and the Great Recession. Indeed, preceding the Great Recession, house prices doubled from 1991 to 2005, while households increased their consumption financed with home equity lines of credit by $\$ 530$ billion annually. In the meantime the demand for residential construction grew from supporting $4.2 \%$ of all U.S. employment in 1996 to $5.1 \%$ of total employment in 2005 (Byun, 2010). Following the burst of the "housing bubble," residential construction-related employment fell to $3.0 \%$ of total U.S. jobs, while home equity extraction plummeted. Moreover, the spending decline during the Great Recession was concentrated in counties that experienced the largest house price declines, which led to employment losses throughout the entire economy (Mian and Sufi, 2014a).

The objective of this paper is to incorporate borrowing constraints into a model with frictional labor and goods markets. We focus on financial frictions that affect households' ability to borrow when facing unforeseen spending shocks. Specifically, we emphasize consumer loans collateralized with residential properties because housing wealth is the main source of collateral to households - it represents about one-half of total household net worth (Iacoviello, 2011) — and the availability of such loans increased steadily over time during the housing boom. According to Greenspan and Kennedy (2007), expenditures financed with home equity extraction increased from $3.13 \%$ of disposable income in 1991 to $8.29 \%$ in $2005 .^{1,2}$ We will study, both analytically and quantitatively, how financial innovations and deregulation that make housing assets more liquid affect equilibrium unemployment, labor market flows and sectoral reallocations, and house prices. We then consider whether our model can account for the magnitude of the changes in unemployment and house prices during the housing boom that preceded the Great Recession and the housing market crash

\footnotetext{
${ }^{1}$ Dugan (2008) explain the increase in home equity loans by the fact that underwriting standards have been relaxed to help more people to qualify for loans. Ducca et al. (2011) attribute the steady increase in average loan-to-value ratios in the U.S. to two financial innovations: the development of collateralized debt obligations and credit default swap protection. Abdallah and Lastrapes (2012) document a constitutional amendment in 1997-98 in Texas that relaxed severe restrictions on home equity lending. Prior to 1997 lenders were prohibited from foreclosing on home mortgages except for the original purchase of the home and home improvements.

${ }^{2}$ Mian and Sufi (2009) estimate that the average U.S. homeowner extracted 25 to 30 cents for every dollar increase in home equity from 2002 to 2006. They argue that the extracted money was not used to pay down debt or purchase new real estate but for real outlays. Moreover, Mian and Sufi (2014b) find that this marginal propensity to borrow is the largest for homeowners with the lowest cash on hand. Using household level data for the U.K., Campbell and Cocco (2007) find that a large positive effect of house prices on consumption of old households who are homeowners - the house price elasticity of consumption can be up to 1.7-and an effect that is close to zero for the cohort of young households who are renters. Moreover, they find that consumption responds to predictable changes in house prices, which is consistent with a borrowing constraint channel.
} 
that followed.

Our model is a two-sector version of the Mortensen-Pissarides (1994) framework augmented to incorporate a housing market and a goods market with explicit financial frictions. In each period, frictional labor and goods markets open sequentially, as in Berentsen, Menzio, and Wright (2011). The frictional labor market is divided into a construction sector where firms produce houses and a general sector where firms produce consumption goods. A fraction of the consumption goods are sold in a decentralized retail market where firms and consumers search for each other and both have some market power. Those households that are liquidity constrained (formally, a fraction of households do not have access to unsecured credit) can use their home as collateral to finance idiosyncratic spending shocks. Therefore, homes have a dual role: (i) they provide housing services that can be traded competitively in a rental market; and, (ii) they provide liquidity services by serving as collateral for consumer loans in the decentralized goods market. The model is summarized in Figure 1.

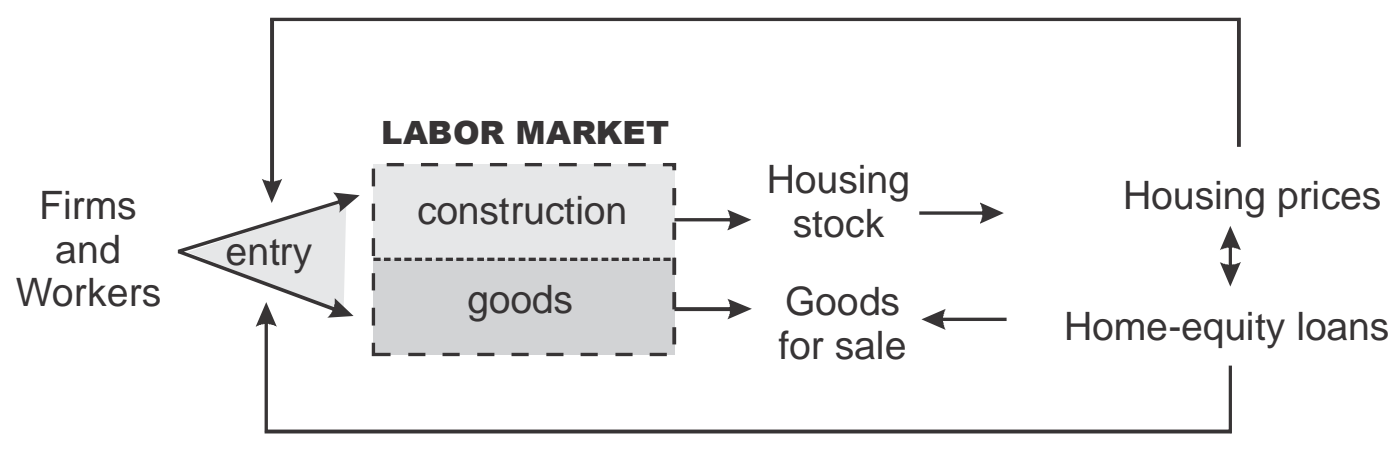

Figure 1: Sketch of the model

An increase in households' access to home equity-based borrowing affects the economy through two main channels. First, households have a higher borrowing capacity when random consumption opportunities occur, which raises firms' expected revenue in the goods market. This effect is akin to an increase in productivity in the goods producing sector. Second, financial innovations affect the demand for homes and, via market clearing, their production and price. These changes in the value and stock of housing can amplify the initial shock to households' borrowing capacity.

In order to build some intuition, we isolate first the home equity-based borrowing channel by shutting down the construction sector and by assuming a fixed supply of houses. If housing assets are scarce or lending standards are sufficiently tight, then house prices exhibit a liquidity premium, i.e., houses are priced above the discounted sum of their future rents. There are conditions on fundamentals under which the economy has 
multiple steady-state equilibria across which unemployment and house prices are negatively correlated. Intuitively, firms' decision to open job vacancies in the retail sector depends positively on households' borrowing capacity and hence home equity. But households' demand for homes as collateral also depends positively on the aggregate activity in the retail sector, thereby creating strategic complementarities between households' and firms' decisions. A new regulation that increases the eligibility of homes as collateral raises the housing liquidity premium and reduces unemployment.

We next re-open the construction sector, so that the supply of homes is endogenous. We consider two polar cases that allow us to identify the conditions under which the unemployment rate is affected by aggregate demand in the goods market: a "competitive" case where firms have no market power in the retail market, and a "monopoly" case where firms have all the market power. In the competitive case, house prices, which are determined by the relative productivities in the two sectors, are unaffected by financial innovations. Relaxing lending standards does not affect unemployment but it does lead to a reallocation of workers toward the construction sector. In the monopoly case, housing assets are priced at their "fundamental" value - the discounted sum of the rental rates. An increase in the eligibility of homes as collateral reduces aggregate unemployment, increases house prices, and drives workers away from the construction sector.

To conclude our analysis we calibrate the model to the U.S. economy over the period 1996 to 2010. The calibration of the labor market is standard based on targets coming from the Job Openings and Labor Turnover Survey (JOLTS). In addition we adopt two key targets: the ratio of household equity-financed expenditure to disposable income from Greenspan and Kennedy (2007), and the ratio of the aggregate housing stock to GDP based on the Federal Reserve's Flow of Funds. Our experiments consist of using a simple identity for the share of consumption financed through home equity extraction to estimate changes in the eligibility of homes as collateral over the period. We feed this sequence of eligibility coefficients into the model and solve for the dynamic equilibrium path under rational expectations. While the model broadly captures the trend features of U.S. data over the period it fails to account for the magnitude of house price changes observed in the data and, as a result, it generates insufficient volatility in the aggregate unemployment rate.

Macroeconomic models under rational expectations are notorious for having a hard time explaining the dynamics of house prices and the dynamics of job openings and unemployment. Thus, in order to properly match U.S. data we replace our perfect foresight assumption with an adaptive learning rule, in the spirit of Evans and Honkapohja (2001) and Hommes (2013), that has been able to generate large swings in asset 
prices and excess volatility in other contexts. ${ }^{3}$ We calibrate the learning model to U.S. data, solve for the learning path and show that the model generates a house price boom of the same magnitude as exhibited in the data. Moreover, the model provides a good fit to sectoral labor flows and the unemployment rate.

\section{$1.1 \quad$ Related literature}

Our study is related to research on unemployment and financial frictions. Wasmer and Weil (2004) and Petrosky-Nadeau (2013) extend the Mortensen-Pissarides model to incorporate a credit market where firms search for investors in order to finance the cost of opening a job vacancy. Our model differs from that literature in that in ours the credit frictions affect households, taking the form of limited commitment and lack of record-keeping, rather than search frictions between lenders and borrowers. We also explicitly formalize a frictional goods market.

Our paper is also related to the literature on unemployment and money. Shi (1998) constructs a model with frictional labor and goods markets where large households insure their members against idiosyncratic risks in both markets. Berentsen, Menzio, and Wright (2011) have a related model in which individuals endowed with quasi-linear preferences readjust their money holdings in a competitive market that opens periodically as in Lagos and Wright (2005). ${ }^{4}$ In Rocheteau, Rupert, and Wright (2007) only the goods market is subject to search frictions but unemployment emerges due to indivisible labor. In all of these models credit is not incentive feasible because of the lack of record keeping and, therefore, fiat money plays a role in overcoming a double-coincidence of wants problem in the goods market. Our model adopts structure similar to Berentsen, Menzio, and Wright (2011), but we add a construction sector and a housing market and introduce home equity-based borrowing in the decentralized goods market.

The macroeconomic implications of the dual role of assets as collateral have been explored in a series of papers, starting with Kiyotaki and Moore (1997). Applications to the recent financial crisis include Midrigan and Philippon (2011) and Garriga et al. (2012) based on standard neoclassical models. Our formalization follows the search-theoretic approach to liquidity and financial frictions, including Ferraris and Watanabe (2008), Lagos (2010, 2011), and Rocheteau and Wright (2013). In addition we formalize a two-sector frictional labor market and unemployment. ${ }^{5}$

\footnotetext{
${ }^{3}$ See, for example, Timmermann (1994) and Branch and Evans (2011).

${ }^{4}$ Rocheteau and Wright $(2005,2013)$ extended the Lagos-Wright model to allow for the free entry of sellers/firms in a decentralized goods market. This free-entry condition was reminiscent of the one in the Pissarides model. Berentsen, Menzio, and Wright (2011) tightened the connection to the labor search literature by requiring that firms search for indivisible labor in a market with matching frictions before entering the goods markets.

${ }^{5}$ In Rocheteau and Wright (2013) the asset used as collateral is a Lucas tree. He, Wright, and Yu (2013) reinterpret the model as one where the asset enters the utility function directly. As we show in this paper, provided that there is a rental market for homes the two interpretations are equivalent.
} 
The first search model to account for sectoral reallocation is Lucas and Prescott (1974). In this model sectoral labor markets are competitive and workers' mobility across sectors is limited. Models in which sectoral labor markets have search frictions include Phelan and Trejos (2000) and Chang (2012). Relative to this literature our model explains workers' reallocation across sectors by changes in financial conditions.

Finally, there is a literature linking households' transitions in the labor and housing markets. For instance, Rupert and Wasmer (2012) explain differences in labor market mobility between the United States and Europe by differences in commuting costs. Head and Lloyd-Ellis (2011) develop a model with search frictions in both housing and labor markets. Karahan and Rhee (2012) consider a two-city model where the low mobility of highly leveraged homeowners reduces the reallocation of labor. None of these models study the joint determination of house prices and unemployment in liquidity-constrained economies.

This paper is also related to a burgeoning literature that incorporates constant gain adaptive learning in studies of monetary policy and asset pricing: see, for example, Branch and Evans (2011); Sargent (1999). ${ }^{6}$ Branch (2014), in particular, studies a related search-based asset pricing model subject to stochastic dividends and asset supply. In this model, asset price booms and crashes can arise as an over-shooting in response to structural changes in the liquidity properties of the asset or as an endogenous response to fundamental shocks.

\section{Environment}

The set of agents consists of a $[0,1]$ continuum of households and a large continuum of firms. Time is discrete and is indexed by $t \in \mathbb{N}$. Each period of time is divided into three stages. In the first stage, households and firms trade indivisible labor services in a labor market (LM) with search and matching frictions. In the second stage, they trade consumption goods in a decentralized market (DM) with home equity-based borrowing. In the last stage, firms sell unsold inventories, debts are settled, wages are paid, households trade assets and housing services in a competitive market $(\mathrm{CM})$, and workers make mobility decisions. We take the consumption good traded in the CM as the numéraire good. The sequence of markets in a representative period is summarized in Figure 2.

The utility of a household is

$$
\mathbb{E} \sum_{t=0}^{\infty} \beta^{t}\left[v\left(y_{t}\right)+c_{t}+\vartheta\left(d_{t}\right)\right],
$$

where $\beta=\frac{1}{1+r} \in(0,1)$ is a discount factor, $y_{t} \in \mathbb{R}_{+}$is the consumption of the DM good, $c_{t} \in \mathbb{R}$ is the

\footnotetext{
${ }^{6}$ For an early contribution see Marcet and Sargent (1989) and for an exhaustive treatment see Evans and Honkapohja (2001).
} 


\section{Labor Market}

\begin{tabular}{|l|}
\multicolumn{1}{|c|}{$(\mathbf{L M )}$} \\
\hline - Entry of firms \\
- Matching of \\
workers and firms \\
- Wage bargaining
\end{tabular}

\section{Decentralized Goods Market}

\begin{tabular}{l|c|}
\hline (DM) \\
\hline - Matching of firms and consumers \\
- Home equity-based borrowing \\
- Negotiation of prices and quantities
\end{tabular}

\section{Competitive Markets} Settlement

Figure 2: Timing of a representative period

consumption of the numéraire good, and $d_{t}$ is the consumption of housing services. ${ }^{7}$ The utility function in the DM, $v\left(y_{t}\right)$, is twice continuously differentiable, strictly increasing, and concave, with $v(0)=0, v^{\prime}(0)=\infty$, and $v^{\prime}(\infty)=0$. We denote $y^{*}>0$ the quantity such that $v^{\prime}\left(y^{*}\right)=1$. The utility for housing services is increasing and concave with $\vartheta^{\prime}(0)=\infty$ and $\vartheta^{\prime}(\infty)=0$.

There are two sectors in the economy denoted by $\chi \in\{g, h\}$ : a sector producing perishable consumption goods $(\chi=g)$, and a sector producing durable housing goods $(\chi=h)$. Firms are free to enter either sector. Each firm is composed of one job. In order to participate in the LM at $t$, firms must advertise a vacant position, which costs $k^{\chi}>0$ units of the numéraire good at $t-1 .^{8}$

Households have sector-specific skills allowing them to work in a given sector. At the end of a period, each household from sector $\chi$ who is unemployed can make a human capital investment, $i \in[0,1]$, in order to migrate to sector $\chi^{\prime}$ with probability $i$. The cost of this investment in terms of the numéraire good is $\Phi(i)$, with $\Phi^{\prime}>0, \Phi^{\prime \prime}>0, \Phi^{\prime}(0)=0$ and $\Phi^{\prime}(1)=+\infty$. The assumption $\Phi^{\prime}(0)=0$ will guarantee that at a steady state households are indifferent between the two sectors. ${ }^{9}$ We denote $\mathcal{P}_{t}^{\chi}$ the measure of households in sector $\chi$ at the beginning of $t$.

The measure of matches between vacant jobs and unemployed households in period $t$ is given by $m^{\chi}\left(s_{t}^{\chi}, o_{t}^{\chi}\right)$, where $s_{t}^{\chi}$ is the measure of job seekers in sector $\chi$ and $o_{t}^{\chi}$ is the measure of vacant firms (openings). The

\footnotetext{
${ }^{7}$ We do not impose the nonnegativity of $c$ in the CM. If $c<0$, the household produces the numéraire good. In this case $c<0$ can be interpreted as self-employment or as a reduction in the household's illiquid wealth (i.e., wealth that cannot serve as collateral in the DM). One can also impose conditions on primitives so that $c \geq 0$ holds, e.g., by assuming sufficiently large endowments of the numéraire good in every period. As in Mortensen and Pissarides (1994) and Lagos and Wright (2005) this assumption of quasi-linear utility makes the model tractable. In our context it implies that trading histories in both the labor and goods market do not matter for households' choice of asset holdings in the CM. As a result, equilibria will feature degenerate distribution of asset holdings. Under strictly concave preferences households would accumulate precautionary savings because of both idiosyncratic shocks in the labor and goods market, and the dynamics of individual asset holdings would become much more complex. Even though households in our analysis will have no need for insurance due to idiosyncratic employment risk they will have a precautionary demand for assets due to idiosyncratic spending shocks. While wealth effects and employment risks are important our analysis emphasizes an "aggregate demand" channel according to which the availability of collateralized loans to households affects firms' expected revenue.

${ }^{8}$ An alternative assumption is that recruiting is labor intensive (instead of goods intensive). In our context our assumption implies that changes in lending standards and financial frictions do not affect the cost of hiring, such as wages of workers in human resources.

${ }^{9}$ For a similar formalization of the mobility decision in a two-sector labor market model, see Chang (2012).
} 
matching function, $m^{\chi}$, has constant returns to scale, and it is strictly increasing and strictly concave with respect to each of its arguments. Moreover, $m^{\chi}\left(0, o_{t}^{\chi}\right)=m^{\chi}\left(s_{t}^{\chi}, 0\right)=0$ and $m^{\chi}\left(s_{t}^{\chi}, o_{t}^{\chi}\right) \leq \min \left(s_{t}^{\chi}, o_{t}^{\chi}\right)$. The job finding probability of an unemployed worker in sector $\chi$ is $p_{t}^{\chi}=m^{\chi}\left(s_{t}^{\chi}, o_{t}^{\chi}\right) / s_{t}^{\chi}=m^{\chi}\left(1, \theta_{t}^{\chi}\right)$ where $\theta_{t}^{\chi} \equiv o_{t}^{\chi} / s_{t}^{\chi}$ is referred to as labor market tightness. The vacancy filling probability for a firm in sector $\chi$ is $f_{t}^{\chi}=m^{\chi}\left(s_{t}^{\chi}, o_{t}^{\chi}\right) / o_{t}^{\chi}=m^{\chi}\left(1 / \theta_{t}^{\chi}, 1\right)$. The employment in sector $\chi$ (measured after the matching phase at the beginning of the DM) is denoted $n_{t}^{\chi}$ and the economy-wide unemployment rate (measured after the matching phase) is $u_{t}$. Therefore,

$$
u_{t}+n_{t}^{g}+n_{t}^{h}=1
$$

The unemployment rate in sector $\chi$ is $1-n_{t}^{\chi} / \mathcal{P}_{t}^{\chi}$. An existing match in sector $\chi$ is destroyed at the beginning of a period with probability $\sigma^{\chi}$. A worker who lost his job in period $t$ becomes a job seeker in period $t+1$. Therefore,

$$
u_{t}=s_{t+1}^{g}+s_{t+1}^{h}
$$

A household that is employed in sector $\chi$ in period $t$ receives a wage in terms of the numéraire good, $w_{1, t}^{\chi}$, paid in the subsequent CM. A household that is unemployed after the matching phase in period $t$ receives an income in terms of the numéraire good, $w_{0}^{\chi}$, interpreted as the sum of unemployment benefits and the value of leisure.

Each filled job in the consumption-good sector produces $\bar{z}^{g} \geq y^{*}$ units of a good that is storable within the period. These goods can be sold and consumed either in the DM or in the CM. In the latter case they are perfect substitutes to the numéraire good. So the opportunity cost of selling $y_{t} \in\left[0, \bar{z}^{g}\right]$ in the DM is $y_{t}$.

The aggregate stock of real estate at the beginning of period $t$ is denoted $A_{t}$. Each filled job in the construction sector produces $\bar{z}^{h}$ units of housing that are added to the existing stock at the end of the period. Housing goods are durable, and each unit of a housing good generates one unit of housing services at the beginning of the CM. These services can be traded in a competitive housing rental market at the price $R_{t}$. Following the rental market and the consumption of housing services, housing assets depreciate at rate $\delta$. While all households can rent housing services, we assume that households are heterogeneous in terms of their access to homeownership. Only a fraction, $\mu$, of households can participate in the market and purchase real estate. Participating households are called homeowners while nonparticipating households are called renters. The market for homeownership opens after the rental market, and housing assets in period $t$ are traded at the price $q_{t}{ }^{10}$

\footnotetext{
${ }^{10}$ Arguably, one would like to introduce search-matching frictions in the housing market as well. We choose to keep this
} 
The DM goods market involves bilateral random matching between retailers (firms) and consumers (households). ${ }^{11}$ Because each firm corresponds to one job, the measure of firms in the goods market in period $t$ is equal to the measure of employed households in the goods producing sector, $n_{t}^{g}$. The matching probabilities for households and firms are $\alpha=\alpha\left(n_{t}^{g}\right)$ and $\alpha\left(n_{t}^{g}\right) / n_{t}^{g}$, respectively. We assume $\alpha^{\prime}>0, \alpha^{\prime \prime}<0$, $\alpha(0)=0, \alpha^{\prime}(0)=1$, and $\alpha(1) \leq 1$. The search frictions in the goods market capture random spending opportunities for households and will generate a precautionary demand for liquid assets. Moreover, the endogenous frequency of trading opportunities, $\alpha\left(n_{t}^{g}\right)$, generates a link between the labor market and the DM goods market: in economies with tight labor markets households experience more frequent trading opportunities.

In a fraction $\zeta$ of all matches there is a technology to enforce debt repayment, in which case consumer loans do not need to be collateralized. In the remaining $1-\zeta$ matches, firms are willing to extend credit to households only if the loan is collateralized with some assets. ${ }^{12}$ In order to formalize home equity extraction, we assume that the only (partially) liquid asset in the DM is housing. ${ }^{13}$ (See the discussion below.) The limited ability to collateralize housing assets is formalized as follows. First, there is a probability, $1-\nu$, that the housing assets of a homeowner are not accepted as collateral. ${ }^{14}$ Second, in accordance with Kiyotaki and Moore (2005), a household that owns $a$ units of housing as collateral can borrow only a fraction of the value of its assets. More specifically, the household can borrow $\rho a_{t}\left[q_{t}(1-\delta)+R_{t}\right]$, where $q_{t}(1-\delta)+R_{t}$ is the value of a home in the DM of period $t$ (the CM price of homes net of depreciation and augmented of the rent), and $\rho \in[0,1]$ captures the limited pledgeability of assets. The parameter, $\rho$, is a loan-to-value ratio which represents various transaction costs and informational asymmetries regarding the resale value of homes. ${ }^{15}$ In case the consumer defaults on the loan, the producer can seize the collateral at the beginning

market competitive for tractability. Moreover, while search-matching frictions are likely to matter for housing prices, we want to focus on the liquidity premium for housing prices arising from home-equity based borrowing and its effect on the goods and labor markets.

${ }^{11}$ The assumption of random bilateral matching and bargaining has several advantages. First, the description of a credit relationship as a bilateral match is more realistic. Second, the existence of a match surplus that can be partially captured by firms creates a stronger channel from home-equity-based consumption and firm's productivity. Third, the idiosyncratic risk generated by the matching process is isomorphic to household preference shocks. In our context the frequency of those shocks is endogenous and depends on the state of the labor market.

${ }^{12}$ Mian and Sufi (2014b) find that the marginal propensity to borrow varies with homeowners' "cash on hand" where they define "cash on hand" as cash holdings, liquid debt capacity, or income that can be easily accessed and converted into spending. In our model households who have access to unsecured credit have the largest "cash on hand" and are not liquidity constrained.

${ }^{13}$ This formalization is analogous to the one in Telyukova and Wright (2008) where some matches have perfect enforcement while others don't. Following Geromichalos, Licari, and Suarez-Lledo (2007), Lagos (2011), or Li and Li (2013) we could introduce fiat money alongside housing assets. We chose to abstract from the coexistence of collateralized loans and currency because our primary focus is not on monetary policy and asset prices.

${ }^{14} \mathrm{~A}$ similar assumption is used in Lagos (2010). For microfoundations for this constraint, see Lester, Postlewaite, and Wright (2012). Taking $\nu$ as exogeneous is consistent with the view that movements in $\nu$ over the recent period are due to regulatory changes (e.g., Dugan, 2008; Abdallah and Lastrapes, 2012).

${ }^{15}$ Microfoundations for such resalability constraints are provided in Rocheteau (2011) based on an adverse selection problem and in Li, Rocheteau, and Weill (2012) based on a moral hazard problem. 
of the CM before it can be rented. We restrict our attention to loans that are repaid within the period in the CM, i.e., the debt is not rolled over across periods.

\section{Equilibrium}

In the following we characterize an equilibrium by moving backward from agents' portfolio problem in the competitive housing and goods markets $(\mathrm{CM})$, to the determination of prices and quantities in the retail goods market (DM), and finally the entry of firms and the determination of wages in the labor market (LM).

\subsection{Housing and goods markets}

Consider a household at the beginning of the CM that owns $a_{t}$ units of housing and has accumulated $b_{t}$ units of debt denominated in the numéraire good to be repaid in the current CM. Let $W_{e, t}^{\chi}\left(a_{t}, b_{t}\right)$ denote its lifetime expected discounted utility in the CM, where $\chi \in\{h, g\}$ represents the sector in which the household is employable, and $e \in\{0,1\}$ is its employment status ( $e=0$ if the household is unemployed, $e=1$ if it is employed). Similarly, let $U_{e, t}^{\chi}\left(a_{t}\right)$ be a household's value function in the LM. The household's problem can be written recursively as:

$$
\begin{gathered}
W_{e, t}^{\chi}\left(a_{t}, b_{t}\right)=\max _{c_{t}, d_{t}, i_{t+1}, a_{t+1}} \mathbb{E}\left\{c_{t}+\vartheta\left(d_{t}\right)+\beta U_{e, t+1}^{\chi_{t+1}}\left(a_{t+1}\right)\right\} \\
\text { s.t. } c_{t}+b_{t}+R_{t} d_{t}+q_{t} a_{t+1}+\Phi\left(i_{t+1}\right)=w_{e, t}^{\chi}+\left[q_{t}(1-\delta)+R_{t}\right] a_{t}+\Delta_{t},
\end{gathered}
$$

where the expectation is with respect to the sector to which the household will be attached in the future, $\chi_{t+1}$. The first term between brackets in equation (4) is the utility of consumption; The second term is the utility of housing services; The third term is the continuation value in the next period. Thus, from (4)-(5), the household chooses its consumption, $c_{t}$, housing services, $d_{t}$, decision to migrate to a different sector, $i_{t+1}$, and real estate holdings, $a_{t+1}$, in order to maximize its lifetime utility subject to a budget constraint. The left side of the budget constraint, (5), is composed of the household's consumption, the repayment of the debt (recall that the debt accumulated in the DM is repaid in the following $\mathrm{CM}$ ), the payment of the rent for housing services, its end-of-period holdings of housing, and its human capital investment to move to a new sector. The right side is the household's income associated with its employment status, $w_{e, t}^{\chi}$, the value of its real estate net of depreciation and augmented for the rental payment, $\left[q_{t}(1-\delta)+R_{t}\right] a_{t}$, and the profits of the firms, $\Delta_{t}$. The distribution of the random variable, $\chi_{t+1}\left(i_{t+1}\right)$, depends on the household's employment 
status, $e_{t}$, and its relocation effort, $i_{t+1}$, as follows:

$$
\begin{aligned}
& \operatorname{Pr}\left(\chi_{t+1}=\chi \mid \chi_{t}=\chi, e_{t}=0\right)=1-\operatorname{Pr}\left(\chi_{t+1}=\chi^{\prime} \mid \chi_{t}=\chi, e_{t}=0\right)=1-i_{t+1} \\
& \operatorname{Pr}\left(\chi_{t+1}=\chi \mid \chi_{t}=\chi, e_{t}=1\right)=1 .
\end{aligned}
$$

So a household can move to a different sector only if it is unemployed. Moreover, its probability to join a new sector is equal to its relocation effort, $i_{t+1}>0$.

Substitute $c_{t}$ from (5) into (4) to obtain

$$
\begin{aligned}
W_{e, t}^{\chi}\left(a_{t}, b_{t}\right)= & {\left[q_{t}(1-\delta)+R_{t}\right] a_{t}-b_{t}+w_{e, t}^{\chi}+\Delta_{t}+\max _{d_{t} \geq 0}\left\{\vartheta\left(d_{t}\right)-R_{t} d_{t}\right\} } \\
& +\max _{i_{t+1}, a_{t+1}}\left\{-q_{t} a_{t+1}-\Phi\left(i_{t+1}\right)+\beta \mathbb{E} U_{e, t+1}^{\chi_{t+1}}\left(a_{t+1}\right)\right\} .
\end{aligned}
$$

In the case where the household does not have access to homeownership the choice of asset holdings is restricted to $a_{t+1}=0$. (The homeownership status is left implicit when writing the value functions.) From (8),$W_{e, t}^{\chi}$ is linear in the household's wealth, which includes its real estate and its labor income net of the debt incurred in the DM; the choice of real estate for the following period, $a_{t+1}$, is independent of the household's asset holdings in the current period, $a_{t}$. Finally, the quantity of housing services rented by the household solves $\vartheta^{\prime}\left(d_{t}\right)=R_{t}$, where $d_{t}$ is independent of both the household's housing wealth and its employment status.

From the last term on the right side of (8), the optimal mobility decision for an unemployed worker in sector $\chi, i_{t+1}^{\chi}$, solves

$$
\Phi^{\prime}\left(i_{t+1}^{\chi}\right)=\max \left\{\beta\left[U_{0, t+1}^{\chi^{\prime}}\left(a_{t+1}\right)-U_{0, t+1}^{\chi}\left(a_{t+1}\right)\right], 0\right\}
$$

From equation (9) the marginal relocation cost must equal the discounted surplus from moving to a different sector. It will be convenient in the following to write the expected discounted surplus of the household net of the cost to acquire new skills as $\Omega(i)=i \Phi^{\prime}(i)-\Phi(i)$.

The expected discounted profits of a firm in the consumption-goods sector in the CM with $x_{t}$ units of inventories (the difference between the $\bar{z}^{g}$ units of good produced in the LM and the $y_{t}$ units sold in the $\mathrm{DM}), b_{t}$ units of a household's debt, and a promise to pay a wage $w_{1, t}^{g}$, are

$$
\Pi_{t}^{g}\left(x_{t}, b_{t}, w_{1, t}^{g}\right)=x_{t}+b_{t}-w_{1, t}^{g}+\beta\left(1-\sigma^{g}\right) J_{t+1}^{g} .
$$

The firm's $x$ units of inventories are worth $x$ units of numéraire good; the household's debt, $b$, is worth $b$ units of numéraire good. So the total value of the firm's sales within the period is $x+b$. In order to compute 
the period profits, we subtract the wage promised to the worker, $w_{1}^{g}$. If the firm remains productive, with probability $1-\sigma^{g}$, then the expected profits of the firm at the beginning of the next period are $J_{t+1}^{g}$. The expected discounted profits of a firm in the housing sector are

$$
\Pi_{t}^{h}\left(w_{1, t}^{h}\right)=\bar{z}^{h} q_{t}-w_{1, t}^{h}+\beta\left(1-\sigma^{h}\right) J_{t+1}^{h} .
$$

A firm in the housing sector produces $\bar{z}^{h}$ units of housing that can be sold at the end of the CM at the price $q_{t}$, and pays the worker a wage $w_{1, t}^{h}$.

\subsection{Home equity loan contract}

We now turn to the retail goods market, DM. Consider a match between a firm and a household holding $a_{t}$ units of housing assets in the DM goods market and suppose that loan repayment cannot be enforced. A home-equity loan contract is a pair, $\left(y_{t}, b_{t}\right)$, that specifies the output produced by the firm for the household, $y_{t}$, and the size of the loan (expressed in the numéraire good) to be repaid by the household in the following $\mathrm{CM}, b_{t}$. The terms of the contract are determined by bilateral bargaining. We use a simple proportional bargaining rule according to which the household's surplus from a match is equal to $\eta /(1-\eta)$ times the surplus of the firm, i.e., $(1-\eta)[v(y)-b]=\eta(b-y)$ where $\eta \in[0,1] .{ }^{16}$ Equivalently, $b=(1-\eta) v(y)+\eta y$. The bargaining solution is

$$
\begin{gathered}
y_{t}=\arg \max _{y} \eta[v(y)-y] \\
\text { s.t. } b(y) \equiv(1-\eta) v(y)+\eta y \leq \rho\left[q_{t}(1-\delta)+R_{t}\right] a_{t} .
\end{gathered}
$$

From (12), output is chosen to maximize the household's surplus, which is a fraction of the total surplus of the match, taking as given the nonlinear pricing rule (13) and subject to the borrowing constraint, $b \leq$ $\rho\left[q_{t}(1-\delta)+R_{t}\right] a_{t}$, according to which the household can only borrow against a fraction of its housing assets. According to (13) the price of one unit of DM output in terms of the numéraire good is $1+(1-\eta)[v(y) / y-1]$, which is decreasing with $y$. The solution to the bargaining problem is $y=y^{*}$ if $b\left(y^{*}\right) \leq \rho[q(1-\delta)+R] a$ and $b(y)=\rho[q(1-\delta)+R] a$ otherwise. Provided that the household has enough borrowing capacity, agents trade the first-best level of output. If the borrowing capacity of the household is not large enough, either because the household doesn't own enough housing wealth or the loan-to-value ratio is too low, the household hits its borrowing constraint and its DM consumption is less than the first-best level.

\footnotetext{
${ }^{16}$ For a review of the merits of the proportional bargaining solution relative to Nash bargaining, see Aruoba, Rocheteau, and Waller (2007).
} 
In a match where debt repayment can be enforced, the debt contract, $(y, b)$, solves (12)-(13) without the inequality on the right side of (13). The solution is $y=y^{*}$ and $b=(1-\eta) v\left(y^{*}\right)+\eta y^{*}$. With perfect credit agents maximize the gains from trade in the DM by producing and consuming the socially efficient quantity, $y^{*}$.

Using the linearity of $W_{e, t}^{\chi}$, the expected discounted utility of a household in the DM holding $a_{t}$ units of housing assets is

$$
V_{e, t}^{\chi}\left(a_{t}\right)=\mathbb{E}\left\{v\left(y_{t}\right)-b\left(y_{t}\right)\right\}+\left[q_{t}(1-\delta)+R_{t}\right] a_{t}+W_{e, t}^{\chi}(0,0),
$$

where the expected surplus in the DM is

$$
\mathbb{E}\left\{v\left(y_{t}\right)-b\left(y_{t}\right)\right\}=\alpha \eta\left\{(1-\zeta) \nu\left[v\left(y_{t}\right)-y_{t}\right]+\zeta\left[v\left(y^{*}\right)-y^{*}\right]\right\}
$$

and where $y_{t}$ depends on the household's housing wealth as indicated by the household's problem, (12)-(13). According to (14) the household is matched with a firm in the retail goods market with probability $\alpha\left(n_{t}^{g}\right)$. With probability, $\zeta$, the household has access to unsecured credit and consumes $y^{*}$. With complement probability, $1-\zeta$, the loan needs to be collateralized, and with probability $\nu$ the seller accepts the housing assets of the buyer as collateral.

\subsection{Labor market}

The description of the labor market corresponds to a two-sector version of the Pissarides (2000) model with imperfect mobility of workers across sectors, as in Chang (2012).

Households. Consider a household with $a_{t}$ units of housing assets that is employed at the beginning of a period. Its lifetime expected utility is

$$
U_{1, t}^{\chi}\left(a_{t}\right)=\left(1-\sigma^{\chi}\right) V_{1, t}^{\chi}\left(a_{t}\right)+\sigma^{\chi} V_{0, t}^{\chi}\left(a_{t}\right), \quad \chi \in\{h, g\}
$$

With probability $1-\sigma^{\chi}$, the household remains employed and offers its labor services to the firm in exchange for a wage in the next CM. With probability $\sigma^{\chi}$, the household loses its job and becomes unemployed. In this case the household will not have a chance to find another job before the next LM in the following period. Substituting $V_{1, t}^{\chi}\left(a_{t}\right)$ and $V_{0, t}^{\chi}\left(a_{t}\right)$ by their expressions given by $(14)$,

$$
U_{1, t}^{\chi}\left(a_{t}\right)=\mathbb{E}\left\{v\left(y_{t}\right)-b\left(y_{t}\right)\right\}+\left[q_{t}(1-\delta)+R_{t}\right] a_{t}+\left(1-\sigma^{\chi}\right) W_{1, t}^{\chi}(0,0)+\sigma^{\chi} W_{0, t}^{\chi}(0,0)
$$

where $y_{t}=y_{t}\left(a_{t}\right)$ is the DM consumption as a function of the household's housing wealth, $a_{t}$. By a similar reasoning the expected lifetime utility of an unemployed household with $a_{t}$ units of housing looking for a job 
in sector $\chi$ is

$$
U_{0, t}^{\chi}\left(a_{t}\right)=\mathbb{E}\left\{v\left(y_{t}\right)-b\left(y_{t}\right)\right\}+\left[q_{t}(1-\delta)+R_{t}\right] a_{t}+W_{0, t}^{\chi}(0,0)+p_{t}^{\chi}\left[W_{1, t}^{\chi}(0,0)-W_{0, t}^{\chi}(0,0)\right],
$$

where $p_{t}^{\chi}$ is the probability of an unemployed in sector $\chi$ finding a job.

Firms. Free entry of firms means that the cost of opening a job vacancy must equalize the discounted expected value of a filled job times the vacancy filling probability, i.e., $k^{\chi}=\beta f_{t}^{\chi} J_{t}^{\chi}$, where $J_{t}^{h}=\Pi_{t}^{h}\left(w_{1, t}^{h}\right)$ and $J_{t}^{g}=\mathbb{E} \Pi_{t}^{g}\left[\bar{z}^{g}-y_{t}, b\left(y_{t}\right), w_{1, t}^{g}\right]$. From equations (10)-(11), we obtain the following recursive formulation for the value of a firm:

$$
J_{t}^{\chi}=z_{t}^{\chi}-w_{1, t}^{\chi}+\beta\left(1-\sigma_{\chi}\right) J_{t+1}^{\chi}
$$

where $z_{t}^{\chi}$ in the case of the goods producing firm is the expected revenue in both the DM and CM of period $t$ expressed in numéraire goods, i.e.,

$$
\begin{aligned}
z_{t}^{g} & =\frac{\alpha\left(n_{t}^{g}\right)}{n_{t}^{g}}(1-\eta)\left\{(1-\zeta) \mu \nu\left[v\left(y_{t}\right)-y_{t}\right]+\zeta\left[v\left(y^{*}\right)-y^{*}\right]\right\}+\bar{z}^{g} \\
z_{t}^{h} & =\bar{z}^{h} q_{t} .
\end{aligned}
$$

From (18), the value of a filled job is equal to the expected revenue of the firm net of the wage plus the expected discounted profits of the job if it is not destroyed, with probability $1-\sigma^{\chi}$. The revenue of the firm in (19) corresponds to the expected surplus of the firm in the DM plus the output sold in the CM if the firm does not find a consumer in the DM. The firm enjoys a fraction, $(1-\eta)$, of the match surplus in the DM if it meets a consumer, with probability $\alpha\left(n_{t}^{g}\right) / n_{t}^{g}$. The size of the match surplus depends on the DM output, which depends on the borrowing capacity of the household. In (19) we assume (and verify later) that all homeowners hold the same quantity of housing assets, irrespective of their labor status, and hence can purchase the same quantity of output, $y_{t}$. In the fraction $\zeta$ where credit repayment can be enforced, the firm sells $y^{*}$ to the household.

Wage. The wage is determined every period according to the following rent sharing rule: $V_{1, t}^{\chi}-V_{0, t}^{\chi}=$ $\lambda^{\chi} J_{t}^{\chi} /\left(1-\lambda^{\chi}\right)$, where $\lambda^{\chi} \in[0,1]$ is the household's bargaining power in the labor market of sector $\chi$. (This rule is consistent with both Nash and Kalai bargaining.) After some straightforward manipulation we show in the Appendix that the wage equation is

$$
w_{1, t}^{\chi}=\lambda z_{t}^{\chi}+\left(1-\lambda^{\chi}\right) w_{0}^{\chi}+\lambda^{\chi} \theta_{t+1}^{\chi} k^{\chi}+\left(1-\lambda^{\chi}\right) \Omega\left(i_{t+1}^{\chi}\right) .
$$


The wage is a weighted average of a firm's revenue, $z_{t}^{\chi}$, and a household's flow utility from being unemployed, $w_{0}^{\chi}$, augmented by a term proportional to firms' average recruiting expenses per unemployed worker, $\theta_{t+1}^{\chi} k^{\chi}$. There are two novelties relative to the standard Pissarides model. First, the firm's marginal revenue is endogenous and will depend on frictions in the DM market and house prices. Second, the last component of the wage equation captures the fact that households in a shrinking sector can ask for a higher wage given that they have the (costly) possibility of moving to the expanding sector.

Sectoral reallocation The worker's mobility decision is determined by the size of the surplus from moving to another sector, $\Delta U_{t}^{\chi} \equiv \beta\left(U_{0, t}^{\chi^{\prime}}-U_{0, t}^{\chi}\right)$ with $\chi^{\prime} \neq \chi$. Following some straightforward calculation (see Appendix), $\Delta U_{t}^{\chi}$ obeys the following recursion:

$$
\Delta U_{t}^{\chi}=\beta\left[w_{0}^{\chi^{\prime}}-w_{0}^{\chi}+\Omega\left(i_{t+1}^{\chi^{\prime}}\right)-\Omega\left(i_{t+1}^{\chi}\right)+\Delta U_{t+1}^{\chi}\right]+\frac{\lambda^{\chi^{\prime}}}{1-\lambda^{\chi^{\prime}}} \theta_{t}^{\chi^{\prime}} k^{\chi^{\prime}}-\frac{\lambda^{\chi}}{1-\lambda^{\chi}} \theta_{t}^{\chi} k^{\chi} .
$$

From (9), the optimal reallocation decision is given by

$$
\Phi^{\prime}\left(i_{t}^{\chi}\right)=\max \left\{\Delta U_{t}^{\chi}, 0\right\}
$$

In an equilibrium where there is reallocation of households from sector $\chi$ to sector $\chi^{\prime}$, i.e, $\Delta U_{t}^{\chi}>0$ for all $t$, the intensity of the reallocation, $i_{t}^{\chi}$, solves

$$
\Phi^{\prime}\left(i_{t}^{\chi}\right)=\beta\left[w_{0}^{\chi^{\prime}}-w_{0}^{\chi}-\Omega\left(i_{t+1}^{\chi}\right)+\Phi^{\prime}\left(i_{t+1}^{\chi}\right)\right]+\frac{\lambda^{\chi^{\prime}}}{1-\lambda^{\chi^{\prime}}} \theta_{t}^{\chi^{\prime}} k^{\chi^{\prime}}-\frac{\lambda^{\chi}}{1-\lambda^{\chi}} \theta_{t}^{\chi} k^{\chi} .
$$

In the case of perfect mobility across sectors, $\Phi=\Phi^{\prime}=0$,

$$
\beta w_{0}^{g}+\frac{\lambda^{g}}{1-\lambda^{g}} \theta_{t}^{g} k^{g}=\beta w_{0}^{h}+\frac{\lambda^{h}}{1-\lambda^{h}} \theta_{t}^{h} k^{h}
$$

If sectors are symmetric in terms of income when unemployed, $w_{0}^{g}=w_{0}^{h}$, bargaining powers, $\lambda^{g}=\lambda^{h}$, and costs of opening job vacancies, $k^{g}=k^{h}$, then $(25)$ reduces to $\theta_{t}^{g}=\theta_{t}^{h}$.

Market tightness. Market tightness is determined by the free-entry condition, $\beta f_{t}^{\chi} J_{t}^{\chi}=k^{\chi}$, where $J_{t}^{\chi}$ is given by (18). Substituting $w_{1, t}^{\chi}$ by its expression from (21) into (18),

$$
\frac{k^{\chi}}{\beta m^{\chi}\left(\frac{1}{\theta_{t}^{\chi}}, 1\right)}=\left(1-\lambda^{\chi}\right)\left[z_{t}^{\chi}-w_{0}^{\chi}-\Omega\left(i_{t+1}^{\chi}\right)\right]-\lambda^{\chi} \theta_{t+1}^{\chi} k^{\chi}+\frac{\left(1-\sigma_{\chi}\right) k^{\chi}}{m^{\chi}\left(\frac{1}{\theta_{t+1}^{\chi}}, 1\right)} .
$$

The financial frictions in the DM affect firms' entry decision in the consumption goods sector through $z^{g}$. If credit is more limited, then households have a lower payment capacity, the price of DM goods falls, which reduces $z^{g}$. As $z^{g}$ is reduced, fewer firms find it profitable to enter the market. 


\subsection{Housing prices}

In order to determine the demand for real estate from homeowners, substitute $U_{e, t}^{\chi}\left(a_{t}\right)$ given by (16) and (17) into (8) — noticing that only the first two terms on the right sides of (16) and (17) depend on $a$ and are independent of $\chi$ and $e$ - to obtain

$$
\max _{a_{t+1} \geq 0}\left\{-\left\{q_{t}-\beta\left[q_{t+1}(1-\delta)+R_{t+1}\right]\right\} a_{t+1}+\beta \alpha \eta(1-\zeta) \nu\left[v\left(y_{t+1}\right)-y_{t+1}\right]\right\}
$$

where $y_{t+1}$ is given by the solution to the bargaining problem in the DM goods market, (12)-(13). According to (27) households choose their holdings of real estate in order to maximize their expected surplus in the DM net of the cost of holding these assets. The cost of holding real estate is approximately equal to the difference between the gross rate of time preference, $\beta^{-1}$, and the gross rate of return of real estate, $\left[(1-\delta) q_{t+1}+R_{t+1}\right] / q_{t}$. Notice that the problem in (27) is independent of the employment status of the household. This suggests that both employed and unemployed households (provided they have access to homeownership) will hold the same quantity of housing assets.

From the bargaining problem in the DM, (12)-(13), $d y_{t+1} / d a_{t+1}=\left[q_{t+1}(1-\delta)+R_{t+1}\right] \rho / b^{\prime}\left(y_{t+1}\right)$, whenever $y_{t+1}<y^{*}$. Therefore, the first-order condition associated with (27), assuming an interior solution, is

$$
q_{t}=\frac{(1-\delta) q_{t+1}+R_{t+1}}{1+r}\left[1+\mathcal{L}\left(n_{t+1}^{g}, y_{t+1}\right)\right]
$$

where we define the liquidity premium for housing assets as

$$
\mathcal{L}\left(n_{t+1}^{g}, y_{t+1}\right)=\alpha\left(n_{t+1}^{g}\right)(1-\zeta) \nu \rho \eta\left[\frac{v^{\prime}\left(y_{t+1}\right)-1}{b^{\prime}\left(y_{t+1}\right)}\right] .
$$

The price of housing is determined by a liquidity-augmented asset pricing equation (28). The price of one unit of housing is equal to its future discounted price net of depreciation plus the rental value of housing services, everything multiplied by the liquidity premium on housing. The liquidity premium, $\mathcal{L}$, measures the increase in the household's surplus in the DM from holding an additional unit of housing wealth.

\subsection{Equilibrium dynamics}

We now provide a definition of dynamic equilibrium for our economy. The population of households is divided according to (2). The dynamics for the population in each sector is

$$
\mathcal{P}_{t+1}^{\chi}=\mathcal{P}_{t}^{\chi}+\left(\mathcal{P}_{t}^{\chi^{\prime}}-n_{t}^{\chi^{\prime}}\right) i_{t+1}^{\chi^{\prime}}-\left(\mathcal{P}_{t}^{\chi}-n_{t}^{\chi}\right) i_{t+1}^{\chi}, \quad \chi \in\{g, h\}
$$


According to (30) the change in the measure of households in sector $\chi, \mathcal{P}_{t+1}^{\chi}-\mathcal{P}_{t}^{\chi}$, is equal to the inflow

from sector $\chi^{\prime},\left(\mathcal{P}_{t}^{\chi^{\prime}}-n_{t}^{\chi^{\prime}}\right) i_{t+1}^{\chi^{\prime}}$, net of the outflow from sector $\chi,\left(\mathcal{P}_{t}^{\chi}-n_{t}^{\chi}\right) i_{t+1}^{\chi}$. The law of motion for the measure of employed in sector $\chi$ is

$$
n_{t+1}^{\chi}=\left(1-\sigma^{\chi}\right) n_{t}^{\chi}+m^{\chi}\left(1, \theta_{t+1}^{\chi}\right) s_{t+1}^{\chi}, \quad \chi \in\{g, h\} .
$$

According to (31) the measure of employed households in sector $\chi$ in period $t+1$, following the matching phase, is equal to the measure of employed households in sector $\chi$ in period $t$ net of the households who lost their jobs in sector $\chi$ at the beginning of $t+1$ plus the measure of job seekers in sector $\chi$ finding a job in $t+1$. The population in sector $\chi$ is divided between employed workers and job seekers,

$$
\mathcal{P}_{t}^{\chi}=n_{t-1}^{\chi}+s_{t}^{\chi}, \quad \chi \in\{g, h\}
$$

Clearing of the housing market implies the quantity of assets held by households with access to homeownership is $a_{t}=A_{t} / \mu$. From (12)-(13) the quantities traded in the DM solve

$$
b\left(y_{t}\right)=\min \left\{\frac{\rho\left[q_{t}(1-\delta)+R_{t}\right] A_{t}}{\mu}, b\left(y^{*}\right)\right\}
$$

From (8) and the clearing of the rental housing market, $d_{t}=A_{t}$, the rental price of housing solves

$$
R_{t}=\vartheta^{\prime}\left(A_{t}\right)
$$

Housing prices solve (28), i.e.,

$$
q_{t}=\frac{(1-\delta) q_{t+1}+\vartheta^{\prime}\left(A_{t+1}\right)}{1+r}\left\{1+\alpha\left(n_{t+1}^{g}\right)(1-\zeta) \nu \rho \eta\left[\frac{v^{\prime}\left(y_{t+1}\right)-1}{b^{\prime}\left(y_{t+1}\right)}\right]\right\}
$$

Finally, the dynamics for the stock of housing are

$$
A_{t+1}=(1-\delta) A_{t}+n_{t}^{h} \bar{z}_{h}
$$

From (36) the stock of housing in $t+1$ is equal to the stock of housing in $t$ net of depreciation augmented by the production of new houses.

Definition 1 An equilibrium is a bounded sequence, $\left\{n_{t}^{\chi}, s_{t}^{\chi}, \theta_{t}^{\chi}, \Delta U_{t}^{\chi}, i_{t}^{\chi}, \mathcal{P}_{t}^{\chi}, q_{t}, y_{t}, R_{t}, A_{t}\right\}_{t=0}^{\infty}$, that solves (2), (22), (23), (26), and (30)-(36).

\section{Sectoral reallocation and home equity-based borrowing}

In order to better understand the mechanics of the model, we will first isolate the effects of sector-specific shocks on the reallocation of jobs by shutting down home equity-based borrowing. Second, we will isolate 
the home equity-based borrowing channel by assuming a fixed supply of housing assets. Finally, we will conclude this section by having two active sectors, and hence an endogenous supply of housing, and home equity-based borrowing together. Throughout this section we restrict ourselves to steady-state equilibria and we set $\zeta=0$ so that all trades in the DM are collateralized.

\subsection{Sectoral reallocation}

In this example, we assume that the two sectors are symmetric in terms of matching technologies, entry costs, incomes when unemployed, bargaining weights, and separation rates, i.e., $m^{g}=m^{h}=m, k^{g}=k^{h}=k$, $w_{0}^{g}=w_{0}^{h}=w_{0}, \lambda^{h}=\lambda^{g}=\lambda$, and $\sigma^{g}=\sigma^{h}=\sigma$. Sectors only differ in their productivity, $\bar{z}^{\chi}$. From (25), and assuming that both sectors are active, $\theta^{g}=\theta^{h}=\theta$ so that households enjoy the same surplus in both sectors. From (26) market tightness solves

$$
\frac{(r+\sigma) k}{m\left(\theta^{-1}, 1\right)}+\lambda \theta k=(1-\lambda)\left(z^{g}-w_{0}\right)
$$

We shut down the home equity-based borrowing channel by setting $\rho=0$ so that housing assets are illiquid and cannot be used to finance consumption in the DM.

The model is solved as follows. From (33) $\rho=0$ implies $y=0$, and from (19), $z^{g}=\bar{z}^{g}$. From (26) $\theta^{g}=\theta^{h}$ implies $\bar{z}^{g}=\bar{z}^{h} q$. Housing prices, $q=\bar{z}^{g} / \bar{z}^{h}$, adjust so that labor productivity in all sectors are equalized. Market tightness is uniquely determined by (37). Moreover, $\theta>0$ if and only if (1 $\lambda)\left(\bar{z}^{g}-w_{0}\right)-(r+\sigma) k>0$. From (28) the rental price of housing is $R=(r+\delta) q=(r+\delta) \bar{z}^{g} / \bar{z}^{h}$, and from (34) the stock of housing is $A=\vartheta^{\prime-1}(R)=\vartheta^{\prime-1}\left[(r+\delta) \bar{z}^{g} / \bar{z}^{h}\right]$. The stock of housing increases with productivity in the construction sector, and it decreases with the real interest rate, the depreciation rate, and the productivity in the consumption goods sector. The size of the housing sector is determined by (36), $n^{h}=\delta A / \bar{z}^{h}=\delta \vartheta^{\prime-1}\left[(r+\delta) \bar{z}^{g} / \bar{z}^{h}\right] / \bar{z}^{h}$. The size of the goods sector is obtained from $(32), n^{h}+n^{g}=1-u$ where from $(31) u(\theta)=\sigma /[m(1, \theta)+\sigma]$. Both sectors are active if $n^{h}<1-u$, i.e.,

$$
\frac{\delta \vartheta^{\prime-1}\left[(r+\delta) \bar{z}^{g} / \bar{z}^{h}\right]}{\bar{z}^{h}}<\frac{m(1, \theta)}{m(1, \theta)+\sigma} .
$$

There is a threshold, $\mathrm{z}>w_{0}+(r+\sigma) k /(1-\lambda)$, for $\bar{z}^{g}$ such that the previous inequality holds with an equality. For all $\bar{z}^{g}>\mathrm{Z}, n^{g}>0$.

Proposition 1 (No home-equity extraction) Suppose that $\rho=0$ and (38) holds. There exists a unique 
steady-state equilibrium with $n^{h}>0$ and $n^{g}>0$. Comparative statics are summarized in the following table:

\begin{tabular}{|l|l|l|l|l|l|l|l|}
\hline & $\bar{z}^{g}$ & $\bar{z}^{h}$ & $\lambda$ & $w_{0}$ & $\sigma$ & $k$ & $\vartheta^{\prime}$ \\
\hline$\theta$ & + & 0 & - & - & - & - & 0 \\
\hline$n^{g}$ & + & $+/-$ & - & - & - & - & - \\
\hline$n^{h}$ & - & $+/-$ & 0 & 0 & 0 & 0 & + \\
\hline$u$ & - & 0 & + & + & + & + & 0 \\
\hline$q$ & + & - & 0 & 0 & 0 & 0 & 0 \\
\hline$A$ & - & + & 0 & 0 & 0 & 0 & + \\
\hline
\end{tabular}

In Figure 3 we represent graphically the determination of the equilibrium. The curve labeled $J C$ (for job creation) indicates the aggregate level of employment, $n^{h}+n^{g}=1-u(\theta)$. As is standard in the MortensenPissarides model, an increase in labor productivity $\left(\bar{z}^{g}\right)$ moves the job creation curve outward, while an increase in a worker's bargaining power $(\lambda)$, income when unemployed $\left(w_{0}\right)$, and a firm's recruiting cost $(k)$ move the job creation curve inward. The curve labeled $N H$ (for $n^{h}$ ) indicates the level of employment in the construction sector. If labor productivity in the goods sector $\left(\bar{z}^{g}\right)$ increases, then $N H$ moves downward, while if the marginal utility of housing services $\left(\vartheta^{\prime}\right)$ increases, then $N H$ moves upward.

We have seen from (19) that a financial innovation that increases households' borrowing capacity raises firms' productivity in the goods sector. An increase in $\bar{z}^{g}$ leads to higher market tightness and lower unemployment. Labor mobility across sectors guarantees that productivities are equalized: employment increases in the consumption goods sector but decreases in the construction sector. As a result of the decline of the supply of housing assets, rental rates and house prices increase. In Figure 3 the $J C$ curve moves outward while the $N H$ curve moves downward.

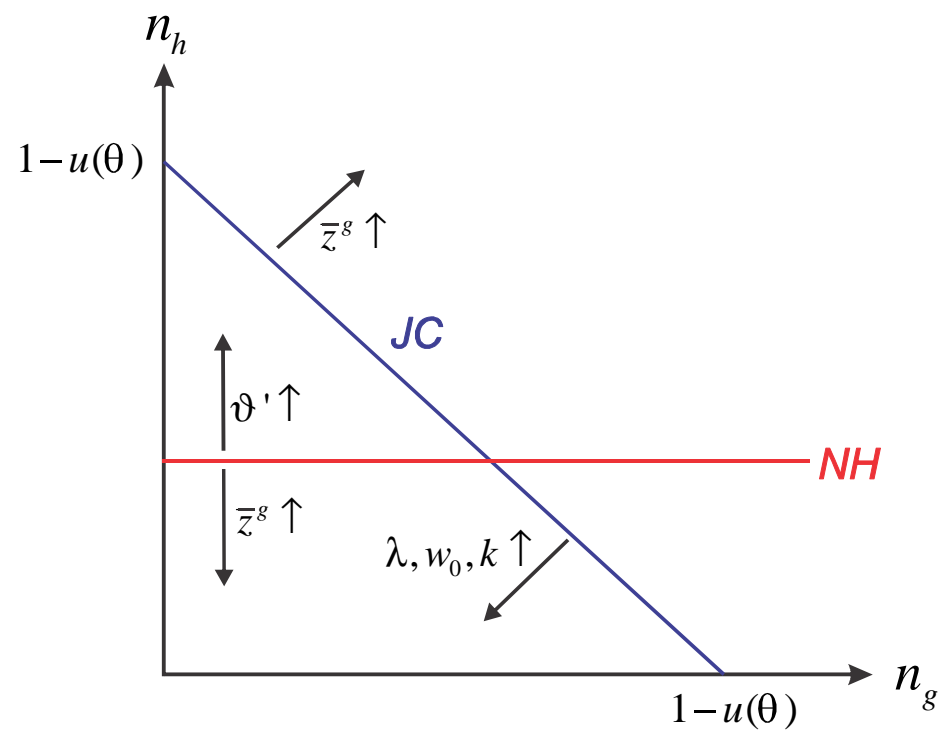

Figure 3: Equilibrium with no equity extraction 
A second effect from a financial innovation that allows households to use homes as collateral is to increase the marginal value of housing assets for homeowners. As a first pass - before we study this effect explicitly in the next section — we consider an increase of the marginal utility for housing services, $\vartheta^{\prime}$. The productivities in the two sectors are unchanged. Therefore, market tightness and unemployment are unaffected. Graphically, the curve $J C$ does not shift. The increase in the demand for housing services generates a reallocation of labor toward the construction sector. Graphically, the curve $N H$ moves upward. In the long run the stock of housing increases.

\subsection{Home equity-based borrowing}

In order to isolate the home equity-based borrowing channel, we now consider the case of a one-sector economy with a fixed stock of housing, $A$. We set the depreciation rate to $\delta=0$ and omit all the superscripts indicating the sector $\chi=g$.

We first show that a steady-state equilibrium can be summarized by two equations that determine market tightness, $\theta$, and house prices, $q$. From (19) and (37) market tightness solves

$$
\frac{(r+\sigma) k}{m\left(\theta^{-1}, 1\right)}+\lambda \theta k=(1-\lambda)\left\{\frac{\nu \alpha[n(\theta)]}{n(\theta)} \mu(1-\eta)[v(y)-y]+\bar{z}-w_{0}\right\}
$$

where $n(\theta)=m(1, \theta) /[m(1, \theta)+\sigma]$ is an increasing function of $\theta$ with $n(0)=0$, and $y$ is determined by $(33)$. We impose the following inequality:

$$
\nu \mu(1-\eta)\left[v\left(y^{*}\right)-y^{*}\right]+\bar{z}-w_{0}>\frac{(r+\sigma) k}{1-\lambda}
$$

Condition (40) guarantees that there is a positive measure of firms participating in the labor market if households are not liquidity constrained. Let $\bar{q}$ be the house price above which homeowners have enough wealth to purchase $y^{*}$ in the DM, i.e., $(\bar{q}+R) \rho A / \mu=b\left(y^{*}\right)$ if $R \rho A / \mu<b\left(y^{*}\right)$ and $\bar{q}=0$ otherwise. For all $q>\bar{q}, y=y^{*}$ and $\theta=\bar{\theta}$, where $\bar{\theta}$ is the unique solution to (39) with $y=y^{*}$. In this case the liquidity provided by the housing stock is abundant and homeowners can trade the first-best level of output in the DM. In contrast, for all $q<\bar{q}$, liquidity is scarce and $y<y^{*}$ is increasing with $q$ so that (39) gives a positive relationship between $\theta$ and $q$ (provided that $\theta>0$ ). Intuitively, higher house prices allow households to finance a higher level of DM consumption, which raises firms' expected revenue and therefore the entry of firms in the labor market. The condition (39) is represented by the curve $J C$ (job creation) in Figure 4.

Let us turn to the determination of house prices. From (28) with $\delta=0$, the price of housing solves

$$
r q=\vartheta^{\prime}(A)+\left[q+\vartheta^{\prime}(A)\right] \alpha[n(\theta)] \nu \rho \eta\left[\frac{v^{\prime}(y)-1}{b^{\prime}(y)}\right] .
$$


If $\theta=0$, then $\alpha[n(\theta)]=0$ and homes are priced at their "fundamental" value, $q=q^{*}=\vartheta^{\prime}(A) / r$. Suppose $q^{*} \geq \bar{q}$, i.e., the fundamental price of housing is large enough to allow households to finance $y^{*}$ in the DM. This condition can be expressed in terms of fundamentals as

$$
\vartheta^{\prime}(A) A \geq \frac{r \mu b\left(y^{*}\right)}{(1+r) \rho}
$$

If (42) holds, then $q=q^{*}$ and $\theta=\bar{\theta}$. Suppose next that $q^{*}<\bar{q}$, i.e., (42) does not hold. From (41) there is a positive relationship between house prices and market tightness. ${ }^{17}$ If the labor market is tight, then households have frequent trading opportunities in the DM. As a consequence, they have a high value for the liquidity services provided by homes and $q>q^{*}$ increases. As $\theta$ tends to infinity, $q$ approaches some limit $\hat{q}>q^{*}$. The condition (41) is represented by the curve $H P$ (house prices) in Figure 4.
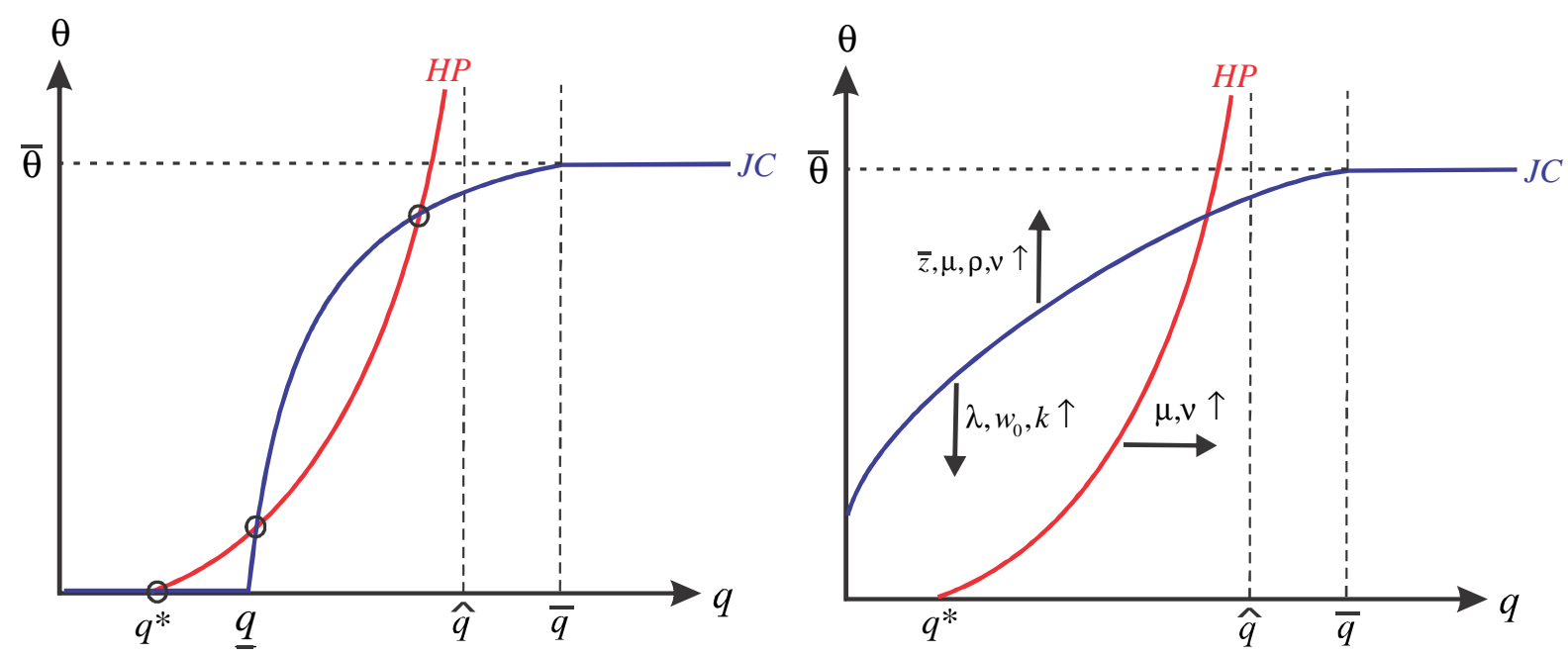

Figure 4: Fixed supply of housing. Left: Multiple steady-state equilibria. Right: Comparative statics.

As shown in Figure 4 the two equilibrium conditions, (39) and (41), are upward sloping. So a steadystate equilibrium might not be unique. In the left panel of Figure 4 we represent a case with two active equilibria. Across equilibria there is a negative correlation between house prices and unemployment. Similar multiplicity has been analyzed in Rocheteau and Wright's (2005, 2013) models of liquidity with free-entry of sellers. If the following condition holds,

$$
\nu \mu(1-\eta)\left\{v\left[y\left(q^{*}\right)\right]-y\left(q^{*}\right)\right\}+\bar{z}-w_{0} \leq \frac{(r+\sigma) k}{1-\lambda}
$$

then there is an equilibrium with an inactive labor market, $\theta=0$, where homes are priced at their fundamental

\footnotetext{
${ }^{17}$ To see this, notice that $(41)$ can be rewritten as $\left[r q-\vartheta^{\prime}(A)\right] /\left[q+\vartheta^{\prime}(A)\right]=\alpha[n(\theta)] \nu \rho \eta\left[v^{\prime}(y)-1\right] / b^{\prime}(y)$, where $\left[v^{\prime}(y)-1\right] / b^{\prime}(y)$ is decreasing in $y$ and $y$ is increasing with $q$. So the left side of the equality is increasing in $q$, while the right side is decreasing in $q$. A higher value of market tightness raises the right side, which leads to a higher value for $q$.
} 
value, $q=q^{*}$. Indeed, if $q=q^{*}$, then firms do not open vacancies and, as a consequence, homes have no liquidity role. There are also an even number of equilibria (possibly zero) with $\theta>0$ and $q>q^{*}$. We summarize our results in the following proposition.

Proposition 2 (Fixed supply of housing) Suppose (40) holds.

1. If $\vartheta^{\prime}(A) A \geq r \mu b\left(y^{*}\right) /(1+r) \rho$, then there is a unique steady-state equilibrium with $q=q^{*}=\vartheta^{\prime}(A) / r$, $y=y^{*}$, and $\theta=\bar{\theta}>0$.

2. Suppose $\vartheta^{\prime}(A) A<r \mu b\left(y^{*}\right) /(1+r) \rho$.

(a) If (43) fails to hold, then $q>q^{*}, y \in\left(0, y^{*}\right)$, and $\theta>0$ at any steady-state equilibrium.

(b) If (43) holds, then there is an inactive equilibrium, $q=q^{*}$ and $\theta=0$, and an even number of active equilibria with $q>q^{*}, y \in\left(0, y^{*}\right)$, and $\theta \in(0, \bar{\theta})$.

The comparative statics at the highest active equilibrium, if it exists, are given by:

\begin{tabular}{|c|c|c|c|c|c|c|c|c|}
\hline & $\bar{z}$ & $\lambda$ & $w_{0}$ & $\sigma$ & $k$ & $\nu$ & $\rho$ & $\mu$ \\
\hline$\theta$ & + & - & - & - & - & + & + & + \\
\hline$u$ & - & + & + & + & + & - & - & - \\
\hline$q$ & + & - & - & - & - & + & $+/-$ & + \\
\hline
\end{tabular}

When investigating the comparative statics we assume that $\vartheta^{\prime}(A) A<r \mu b\left(y^{*}\right) /(1+r) \rho$, i.e., the supply of housing is scarce in the sense that homeowners do not have enough housing wealth in order to finance $y^{*}$. Consider first a financial innovation that increases the eligibility of homes as collateral. An increase in $\nu$ moves the $H P$ curve to the right because the liquidity premium of homes goes up; it moves the $J C$ curve upward as the frequency of sale opportunities in the DM increases. Consequently, market tightness and house prices increase, and unemployment decreases.

Lax lending standards can also take the form of high loan-to-value ratios. An increase in $\rho$ moves the $J C$ curve upward because households can borrow a larger amount against their home equity, which allows firms to sell more output in the DM. But an increase in $\rho$ has an ambiguous effect on the home-pricing curve, HP. On the one hand, holding the marginal utility of DM consumption constant, households are willing to pay more for housing wealth because they obtain larger loans when their home is used as collateral to finance their DM consumption. On the other hand, the fact that households hold more liquid wealth implies that the wedge between $v^{\prime}$ and the seller's cost, one, is reduced, which leads to a reduction in the size of the liquidity premium. 


\subsection{Sectoral reallocation induced by financial innovations}

We now allow for both home equity financing and an endogenous supply of housing. As in our first example, the two sectors are assumed to be symmetric in terms of matching technologies, entry costs, incomes when unemployed, bargaining weights, and separation rates. Moreover, we assume a logarithmic utility function for housing services, i.e., $\vartheta(A)=\vartheta_{0} \ln (A)$. From (34) the rental price of homes is then $R=\vartheta_{0} / A$. In order to derive analytical results we consider two special cases for the pricing protocol in the DM: a "competitive" case where firms have no market power to set prices; and a "monopoly" case where firms can set prices (or terms of trade) unilaterally. ${ }^{18}$

The "competitive" case. Suppose first that firms have no bargaining power in the DM, $1-\eta=0$. Following the same reasoning as in Section 4.1, the model can be solved recursively. From (19) the firm's productivity in the nonhousing sector is $z^{g}=\bar{z}^{g}$. From (25) and (26) the mobility across sectors implies $\bar{z}^{h} q=\bar{z}^{g}$, i.e., $q=\bar{z}^{g} / \bar{z}^{h}$. Market tightness, which is determined by (37), is not affected by the availability of home equity loans. The size of the housing sector is $n^{h}=\delta A / \bar{z}^{h}=\delta q A / \bar{z}^{g}$, and the size of the nonhousing sector is $n^{g}=1-u(\theta)-n^{h}$. An active goods market, $n^{g}>0$, requires that $A q \in\left[0,[1-u(\theta)] \bar{z}^{g} / \delta\right)$. From (35), $A q$ solves

$$
\frac{(1+r) A q}{(1-\delta) A q+\vartheta_{0}}=1+\nu \alpha\left(1-u(\theta)-\frac{\delta q A}{\bar{z}^{g}}\right) \rho\left[v^{\prime}(y)-1\right],
$$

where from (33), $y=\min \left\{\rho\left[A q(1-\delta)+\vartheta_{0}\right] / \mu, y^{*}\right\}$. An equilibrium with both sectors being active exists and is unique if the left side of (44) evaluated at $A q=[1-u(\theta)] \bar{z}^{g} / \delta$ is greater than the right side of (44) (which equals one for this value of $A q$ ), i.e.,

$$
[1-u(\theta)] \bar{z}^{g}>\frac{\delta \vartheta_{0}}{r+\delta}
$$

This condition requires that the productivity in the goods sector, $\bar{z}^{g}$, is sufficiently large.

If liquidity is abundant, $\rho\left[A q(1-\delta)+\vartheta_{0}\right] / \mu \geq y^{*}$, agents can trade the first best in the DM, $y=$ $y^{*}$, and from (44) $A q=\vartheta_{0} /(r+\delta)$. The condition for such an equilibrium with unconstrained credit is $(1+r) \vartheta_{0} /(r+\delta) \geq \mu y^{*} / \rho$. Suppose in contrast that liquidity is scarce, $(1+r) \vartheta_{0} /(r+\delta)<\mu y^{*} / \rho$. Higher values for $\mu$ or $\nu$ increase the right side of (44). So $A q$ and $n^{h}=\delta q A / \bar{z}^{g}$ increase. Hence if the eligibility for home equity loans increases, or if homeownership increases, then labor is reallocated from the general sector

\footnotetext{
${ }^{18}$ Our "competitive" case should be distinguished from the notion of competitive search where it is assumed that contracts are posted before matches are formed and search is directed. For this concept of equilibrium in a related model, see Rocheteau and Wright (2005).
} 
to the construction sector. For these two experiments changes in financial frictions affect the composition of the labor market, but aggregate employment and unemployment are unchanged.

The "monopoly" case. We now consider the opposite case where households have no bargaining power in the DM goods market, $\eta=0$. Since households do not enjoy any surplus from their DM trades, the asset price has no liquidity premium, $q=\vartheta_{0} / A(r+\delta)$. Households are indifferent in terms of their holdings of housing, so we focus on symmetric equilibria where all homeowners hold $A / \mu$. To simplify the analysis further, assume that the matching function in the DM is linear, $\alpha(n)=n$, so that all firms are matched with one household, $\alpha(n) / n=1$. The productivity in the goods sector is

$$
z^{g}=\mu \nu[v(y)-y]+\bar{z}^{g}
$$

where from $(33), v(y)=\min \left\{\rho\left[A q(1-\delta)+\vartheta_{0}\right] / \mu, v\left(y^{*}\right)\right\}$. Assuming $(1+r) \vartheta_{0} /(r+\delta)<\mu v\left(y^{*}\right) / \rho$, households do not own enough housing assets to trade the efficient output level in the DM. In this case,

$$
v(y)=\frac{\rho \vartheta_{0}(1+r)}{\mu(r+\delta)}
$$

If the LM is active, then market tightness is determined by (37) and (46)-(47),

$$
\frac{(r+\sigma) k}{m\left(\theta^{-1}, 1\right)}+\lambda \theta k=(1-\lambda)\left\{\mu \nu\left[\frac{\rho \vartheta_{0}(1+r)}{\mu(r+\delta)}-v^{-1}\left(\frac{\rho \vartheta_{0}(1+r)}{\mu(r+\delta)}\right)\right]+\bar{z}^{g}-w_{0}\right\}
$$

An increase in the loan-to-value ratio, $\rho$, in the acceptability of homes as collateral, $\nu$, or in homeownership, $\mu$, raises market tightness and aggregate employment.

As before the mobility across sectors implies that $q=z^{g} / \bar{z}^{h}$. The size of the housing sector is determined by $n^{h}=\delta A / \bar{z}^{h}=\delta q A / z^{g}=\delta \vartheta_{0} /(r+\delta) z^{g}$. Therefore, $n^{g}=1-u(\theta)-n^{h}$. An equilibrium with an active goods market exists if

$$
u(\theta)+\frac{\delta \vartheta_{0}}{(r+\delta) z^{g}}<1
$$

where $\theta$ is the solution to (48) and $z^{g}$ is given by (46)-(47). Condition (49) will be satisfied if $\bar{z}^{g}$ is sufficiently large. A reduction in financial frictions (i.e., an increase in $\rho, \nu$, and $\mu$ ) leads to a reallocation of workers from the construction sector to the goods sector. In the context of Figure 3, the $N H$ curve moves downward and the $J C$ curve moves outward as $\rho, \nu$, or $\mu$ increase. We summarize the results above in the following proposition.

Proposition 3 (Financial innovations in two limiting economies.) Assume $\vartheta(A)=\vartheta_{0} \ln (A)$. 
1. Suppose $\eta=1$. If (45) holds, then an equilibrium with two active sectors exists and is unique. If liquidity is scarce, $(1+r) \vartheta_{0} /(r+\delta)<\mu y^{*} / \rho$, an increase in the acceptability of collateral, $\nu$, or homeownership, $\mu$, has no effect on unemployment but it raises employment in the construction sector, $n^{h}$, and reduces employment in the goods sector, $n^{g}$.

2. Suppose $\eta=0$, and $\alpha(n)=n$. If (49) holds, then an equilibrium with two active sectors exists and is unique. If liquidity is scarce, $(1+r) \vartheta_{0} /(r+\delta)<\mu v\left(y^{*}\right) / \rho$, an increase in the acceptability of collateral, $\nu$, the loan-to-value ratio, $\rho$, or homeownership, $\mu$, increases market tightness, $\theta$, aggregate employment, $1-u$, and house prices, $q$, but it reduces employment in the construction sector, $n^{h}$.

\section{Calibration}

We now turn to a quantitative evaluation of the effects of financial innovations and regulations on the labor and housing markets by calibrating our economy to the United States. We interpret, in the context of the model, these innovations/regulations as changes in eligibility criteria for home-equity loans.

\subsection{Calibrating the Labor Market}

The basic unit of time is a month. ${ }^{19}$ The economy is calibrated to the U.S. averages in 1996. However, we use the averages over the period 2000:12 to 2012:9 for transition rates in the labor market as we do not have relevant data prior to the Jobs Opening and Labor Turnover Survey (JOLTS) from the Bureau of Labor and Statistics (BLS). ${ }^{20}$

The average job destruction rates from the JOLTS over this period were $6.1 \%$ per month in the construction sector, $\sigma^{h}=0.061$, and $3.6 \%$ per month in the nonfarm sector, $\sigma^{g}=0.036$. The job finding probabilities are computed from (31) as $p^{\chi}=\sigma^{\chi} n^{\chi} / s^{\chi}$. The BLS Establishment Survey provides construction and nonfarm employment, $E^{h}$ and $E$, respectively, as well as aggregate and construction industry unemployment numbers, $U$ and $U^{h}$, respectively. ${ }^{21}$ We use this information to compute the shares of employment in each sector, as $n^{\chi}=E^{\chi} /(E+U)$ for the year 1996, along with the shares of unemployment. The results are reported in Table 1. Finally, we target a value $f^{g}=0.7$ for the job filling probability in the general sector, corresponding to the value in Den Haan et al. (2000). For the job filling probability in the construction

\footnotetext{
${ }^{19}$ We choose a short unit of time to target transition probabilities in the labor market (in particular vacancy filling probabilities). Even though households in the model repay their loans every period, we reinterpret the model as one where households can stagger the repayment of their loans over multiple periods, and we will choose the average duration between two trading opportunities in the DM to be consistent with the average maturity of home lines of credit.

${ }^{20}$ See Davis et al. (2010) for a discussion of JOLTS data. The data we use are: Total Separations rate - Total Nonfarm (Fred II series I.D. JTSTSR); Total Separations rate - Construction (Fred II series I.D. JTU2300TSR).

${ }^{21}$ The series we use are: All Employees - Total nonfarm (Fred II series I.D. PAYEMS); All Employees - Construction (Fred II series I.D. USCONS); Unemployed (Fred II series I.D. UNEMPLOY).
} 
sector we target $f^{h}=0.85$, in accordance with the evidence in Davis et al. (2010). Given $p^{\chi}$ and $f^{\chi}$, labor market tightness is simply $\theta^{\chi}=p^{\chi} / f^{\chi}$.

Table 1: U.S. Employment, Unemployment and Job Finding Rates for 1996

\begin{tabular}{llll}
\hline $\begin{array}{c}\text { Employment share: } \\
n^{\chi}=E^{\chi} /(E+U)\end{array}$ & Aggregate & Construction & Non-Construction \\
Unemployment share: & $94.30 \%$ & $4.34 \%$ & $89.94 \%$ \\
$s^{\chi}=U^{\chi} /(E+U)$ & $5.75 \%$ & $0.58 \%$ & $5.17 \%$ \\
$\begin{array}{c}\text { Job finding rate } \\
p^{\chi}=\sigma^{\chi} n^{\chi} / s^{\chi}\end{array}$ & & 0.46 & 0.56 \\
\hline
\end{tabular}

Notes: See Appendix for details on data sources.

The matching function takes a Cobb-Douglas specification, $\bar{m}^{\chi}\left(o^{\chi}\right)^{1-\epsilon^{\chi}}\left(s^{\chi}\right)^{\epsilon^{\chi}}$, with $\bar{m}^{\chi}>0$ and $\epsilon^{\chi} \in$ $(0,1)$. The matching elasticity and bargaining share in the housing sector, $\epsilon^{h}=\lambda^{h}$, will be chosen to target a ratio of the housing stock to GDP and to respect a Hosios condition. ${ }^{22}$ The matching elasticity in the general sector is set to $\epsilon^{g}=0.5$ based on the estimates reported in Petrongolo and Pissarides (2001), while the worker's bargaining share is set to $\lambda^{g}=0.10$ to target a $10 \%$ mark-up for goods producing firms in the aggregate. The level parameters of the matching functions are backed out as $\bar{m}^{\chi}=f^{\chi}\left(\theta^{\chi}\right)^{\epsilon^{\chi}}$.

The remaining parameters of the labor market are $w_{0}^{\chi}, \bar{z}^{\chi}$, and $k^{\chi}$. We normalize $\bar{z}^{g}$ and $\bar{z}^{h}$ to 1 . We assume that the income of an unemployed worker, $w_{0}^{\chi}$, has both a fixed and variable component. The fixed component, $l$, corresponds to the utility of leisure or home production. (It will remain fixed in our experiments in the next section.) The variable component is interpreted as benefits that are proportional to wages. Mulligan (2012) estimates a median replacement rate in the United States of $63 \%$, covering the variety of income support programs available to workers. Therefore, $w_{0}^{\chi}=0.63 \times w_{1}^{\chi}+l .{ }^{23}$ We pin down $l$ by requiring that $w_{0}^{\chi}=0.85 z^{\chi}$ following Rudanko (2011). The next section details the strategy for pinning down $k^{g}$, which in turn will determine $k^{h}$ from (25), as part of the calibration of the goods and housing markets.

\subsection{Calibrating the Goods and Housing Markets}

The matching function in the goods market is Cobb-Douglas, $\bar{m}^{d}\left(n^{g}\right)^{1-\epsilon^{d}}$, where $\bar{m}^{d}>0$ and $\epsilon^{d} \in(0,1)$. We assume that sellers and buyers have symmetric contributions to the matching process, setting the elasticity $\epsilon^{d}=0.5$. The consumer's share in bargaining is set to $\eta=0.67 \mathrm{such}$, given the value of other parameters,

\footnotetext{
${ }^{22}$ The Hosios conditions in the labor and goods market guarantee constrained efficiency provided that borrowing constraints do not bind. See, e.g., Petrosky-Nadeau and Wasmer (2011).

${ }^{23}$ For a discussion on how to formalize unemployment income in the long run and the distinction between transfer payments and utility of leisure, see Pissarides (2000, Section 3.2).
} 
the borrowing constraints in pairs requiring a collateralized loan binds. The level parameter of the matching function, $\bar{m}^{d}$, is calibrated to a low frequency of spending shocks, $\alpha$, such that on average consumption events financed by equity occur every 4 to 5 years, i.e., $\alpha=m^{d}\left(n^{g}\right)^{1-\epsilon^{d}}=0.06$. This low frequency is motivated by an average maturity of home lines of credit of 5 years. In addition, we assume that only one quarter of all trades require collateral by setting $\zeta=0.75$.

The eligibility probability of homes as collateral, $0<\nu<1$, is calibrated so that the amount of household equity financed expenditure matches the evidence in Greenspan and Kennedy (2007), who provide quarterly estimates from 1991:1 to 2008:4. That is, we define aggregate consumption expenditure in the DM as $C_{D M} \equiv \mu \alpha \nu[(1-\eta) v(y)+\eta y]$, and disposable income as $Y^{D} \equiv n^{g} z^{g}+n^{h} z^{h}-k^{g} o^{g}-k^{h} o^{h}$. We target $C_{D M} / Y^{D}=0.025$, at the lower end of its value observed for the period of interest. The homeownership rate is set to $\mu=0.654$ as reported for the year 1996 in by the U.S. Census Bureau.

We express the parameter $\rho$ as the product of two components, $\bar{\rho}$ and $\rho_{a}$. We think of $\bar{\rho}$ as a standard loan-to-value (LTV) ratio. Adelino et al. (2012) find that during the period 1998-2001, on average 60\% of transactions where at a LTV of exactly 0.8 . We choose a more conservative value of $\bar{\rho}=0.6$, and we will consider experiments relaxing lending standards. The second component, $\rho_{a}$, is interpreted as the equity share of a home that can be pledged. The Survey of Consumer Finance (2012) indicates that the median household debt secured by a primary residential property of $\$ 112,100$ in 2010 U.S. dollars. The same household holdings of non-financial wealth, amounts to $\$ 209,500$ dollars in a primary residence. ${ }^{24}$ Based on $^{2}$ this, we assume $\rho_{a}=0.5$, resulting in $\rho=\bar{\rho} \times \rho_{a}=0.6 \times 0.5=0.3$.

We choose the bargaining share in the construction sector, $\lambda^{h}$, to target the ratio of the value of the aggregate housing stock to GDP in 1996, before the large run-up in housing prices, $q A /\left(n^{g} z^{g}+n^{h} z^{h}\right)=1.65$, based on the Flow of Fund. ${ }^{25}$ To see why the bargaining share, $\lambda^{h}$, will allow us to reach this target, notice that the target implies relative productivities in the two sectors,

$$
\frac{z^{g}}{z^{h}}=\frac{n^{h}}{n^{g}}\left(\frac{G D P}{\delta q A}-1\right)
$$

where we have used (20) and (36), i.e., $q=\bar{z}^{h} / z^{h}$ and $A=n^{h} \bar{z}_{h} / \delta$, to express the value of the housing stock as $q A=z^{h} n^{h} / \delta$. The depreciation rate of the housing stock over 1996-2001 is taken from the Harding et al.

\footnotetext{
${ }^{24}$ See Survey of Consumer Finance (2012), Table 13 page 59 and Table 9 page 45.

${ }^{25}$ For comparison, this ratio was equal to 2 on average over the period 2000 to 2012 . The data for the U.S. stock of housing: Real Estate - Assets - Balance Sheet of Households and Nonprofit Organizations (FRED series I.D. REABSHNO), billions of dollars. These data comes from the Z.1 Flow of Funds release of the Board of Governors in Table B.100. Model-consistent GDP is constructed as personal consumption expenditures (FRED series I.D. PCE) plus residential investment (FRED series I.D. PRFI). By comparison, Midrigan and Philippon (2001) target a housing stock to consumption expenditure ratio of 2.11.
} 
(2007) estimate of 0.0275 per year, i.e., $\delta=0.0023 .^{26}$

The functional form for the utility of housing services is $\vartheta(A)=\varsigma \ln A$, in accordance with Rosen (1979) and Mankiw and Weil (1989), and the level parameter is $\varsigma=R A$. We compute the rental rate as $R=$ $(R / q)_{\text {data }} \times q$, where the rent to price ratio is given by the Lincoln Institute of Land Policy estimate of $4.92 \% .^{27}$

The utility function in the DM takes the form $v(y)=y^{1-\omega_{1}} /\left(1-\omega_{1}\right)$ with $\omega_{1} \in(0,1)$. We choose $\omega_{1}$ so that the model's liquidity premium is consistent with the one in the data. From (28) we compute the liquidity premium in the data as $\mathcal{L} / q=r+\delta-R / q$. In the model it is given by (29). Therefore,

$$
r+\delta-\frac{R}{q}=\left(1-\delta+\frac{R}{q}\right) \alpha(1-\zeta) \nu \rho \eta\left[\frac{y^{-\omega_{1}}-1}{(1-\eta) y^{-\omega_{1}}+\eta}\right]
$$

where, from $(33), y$ solves $(1-\eta) y^{1-\omega_{1}} /\left(1-\omega_{1}\right)+\eta y=[q(1-\delta)+R] \rho A / \mu$. From (19) this implies a value for the productivity in the goods sector,

$$
z^{g}=\bar{z}^{g}+\frac{\alpha\left(n^{g}\right)}{n^{g}} \nu(1-\zeta)(1-\eta) \mu\left(\frac{y^{1-\omega_{1}}}{1-\omega_{1}}-y\right) .
$$

We make this value consistent with $\theta^{g}$ obtained above and the free-entry condition, (26), by adjusting the vacancy cost parameter, $k^{g}$. Table 2 presents the baseline parameter values.

\footnotetext{
${ }^{26}$ This is lower than the rate of $3.6 \%$ used in Midrigan and Philippon (2011), and greater than the value of $1.6 \%$ in Gomme and Rupert (2007).

${ }^{27}$ The Lincoln Institute of Land Policy provides reliable time series of the Rent-Price ratio, the average ratio of estimated annual rents to house prices for the aggregate stock of housing in the U.S. (the rental data are gross and do not account for income taxes or depreciation).
} 
Table 2: Baseline Calibration

\begin{tabular}{|c|c|c|c|}
\hline \multirow{2}{*}{\multicolumn{4}{|c|}{$\begin{array}{l}\text { Parameter Definition } \\
\text { Panel A: Labor Market Parameters }\end{array}$}} \\
\hline & & & \\
\hline$\sigma^{g}$ & Job destruction rate - general & 0.032 & JOLTS \\
\hline$\sigma^{h}$ & Job destruction rate - housing & 0.061 & JOLTS \\
\hline$w_{0}^{g}$ & Value of non-employment - general & $0.85 z^{g}$ & Rudanko (2011) \\
\hline$w_{0}^{h}$ & Value of non-employment - housing & $0.85 z^{h}$ & Rudanko (2011) \\
\hline$k^{g}$ & Vacancy cost - general goods & 3.17 & Job filling rate \\
\hline$k^{h}$ & Vacancy cost - housing & 1.30 & Job filling rate \\
\hline$\epsilon^{g}$ & Elasticity, labor matching - general & 0.50 & Petrongolo and Pissarides (2001) \\
\hline$\epsilon^{h}$ & Elasticity, labor matching - housing & 0.31 & Hosios condition / Competitive search \\
\hline $\bar{m}^{g}$ & Level, labor matching - general & 0.63 & Job finding rate \\
\hline $\bar{m}^{h}$ & Level, labor matching - housing & 0.71 & Job finding rate \\
\hline$\lambda^{g}$ & Worker's wage bargaining weight & 0.10 & Aggregate markup \\
\hline$\lambda^{h}$ & Worker's wage bargaining weight & 0.31 & Housing stock to GDP \\
\hline \multicolumn{4}{|c|}{ Panel B: Housing Market Parameters } \\
\hline $\bar{z}^{h}$ & Technology in housing sector & 1 & \\
\hline$\mu$ & Home ownership rate & 0.65 & Survey of Consumer Finance \\
\hline$\varsigma$ & Level, housing services utility & 0.14 & Rent to price ratio \\
\hline$\delta$ & Housing stock depreciation rate & 0.002 & Harding et al. (2006) \\
\hline \multicolumn{4}{|c|}{ Panel C: Goods and Credit Market Parameters } \\
\hline $\bar{z}^{g}$ & Technology in general sector & 1 & \\
\hline$\omega_{1}$ & Curvature, DM good utility & 0.98 & Housing liquidity premium \\
\hline$\eta$ & DM bargaining weight, consumer & 0.67 & Binding borrowing constraint \\
\hline $\bar{m}^{d}$ & Level, DM matching function & 0.06 & Frequency of spending opportunities \\
\hline$\epsilon^{d}$ & Curvature, DM matching function & 0.50 & Balanced matching function \\
\hline$\zeta$ & Frequency of credit in DM transactions & 0.75 & \\
\hline$\nu$ & Acceptability of collateral & 0.22 & Equity financed consumption \\
\hline$\rho$ & Loan to value of net equity $\bar{\rho} \times \rho_{a}$ & 0.30 & $\begin{array}{l}\text { Adelino et al (2012) and } \\
\text { net equity for collateral }\end{array}$ \\
\hline
\end{tabular}

\section{Quantitative Results}

We now turn to the quantitative evaluation of the effects of financial innovations and regulations, interpreted as changes in $\nu_{t}$, on the labor and housing markets. We calibrate our model to the U.S. economy focusing on the period 1996-2010. This section reports on the following experiment. We imagine the economy beginning in a steady state in 1996.04, that is, the steady state to which the model was calibrated in the previous section. We then consider a series of permanent, unanticipated shocks to the eligibility of homes as collateral, $\nu$. We estimate the monthly sequence, $\left\{\nu_{t}\right\}_{t=1996.04}^{2008.12}$, to match the model-implied home equity extraction, i.e., the ratio of consumption financed with home equity loans to income, to the data reported in Greenspan and Kennedy (2007), denoted $H E E^{G K}$. In the model, aggregate home equity-financed consumption is 
$\alpha\left(n^{g}\right) \rho[q(1-\delta)+R] A$, and disposable income is $Y^{D} \equiv n^{g} z^{g}+n^{h} z^{h}-k^{g} O^{g}-k^{h} o^{h}$. Hence,

$$
\nu_{t}=\frac{Y_{t}^{D}}{\alpha\left(n_{t}^{g}\right) \rho\left[q_{t}(1-\delta)+R_{t}\right] A_{t}} \times H E E_{t}^{G K}
$$

Figure 5 plots the estimated sequence of $\nu$ 's. The estimated $\nu_{t}$ series exhibits a relaxing of financial constraints with an acceptability ratio of 0.25 in 1996 and peaking in late 2003 before a steady decrease that is accelerated during the financial crisis in 2007-2008. Both the $\nu_{t}$ series and the equity extraction data peak in 20032004, roughly two years in advance of the peak in house prices. ${ }^{28}$ Following the bust in house prices, home equity-financed consumption collapses and so we set $\nu_{t}=0$ over $2009.01-2010.12$. We use the estimated $\left\{\nu_{t}\right\}_{t=1996.04}^{2010.12}$ in the parameterization of the model and study the transitional dynamics under rational expectations and under adaptive learning.

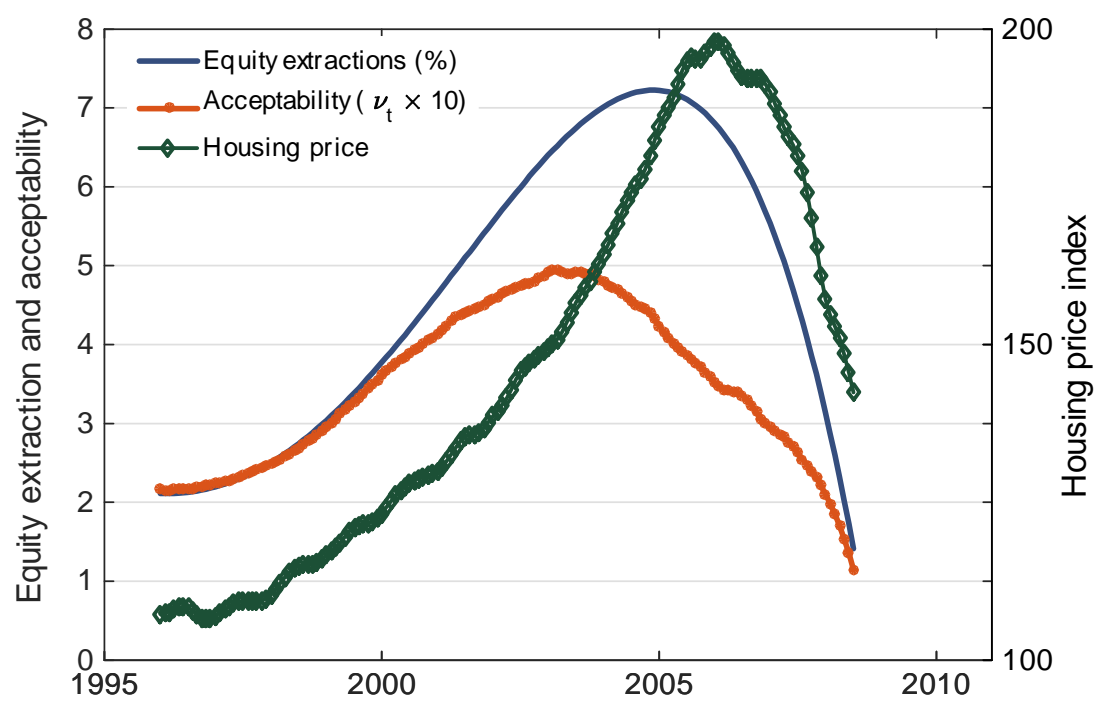

Figure 5: House prices, home equity extraction, and collateral eligibility

\subsection{Perfect foresight}

This section presents equilibrium results under perfect foresight. To solve for the perfect foresight path we proceed as follows. At date $t=1996.05$, we take $\nu_{t}$ from the estimated sequence, assuming the economy is in steady state in $t-1=1996.04$, and solve for the perfect foresight path assuming that $\nu$ will not change over time. ${ }^{29}$ This transition path generates the values for the state variables at $t=1996.06$. We then repeat for

\footnotetext{
${ }^{28}$ These data are from the Federal Housing Finance Agency's index of existing home sale prices.

${ }^{29} \mathrm{On}$ average, it takes 12 periods to transition from one steady state to another. The transition length depends on the distance between steady-state values for the aggregate housing stock $A_{t}$, as with a very small monthly depreciation rate the transition length can be quite slow.
} 
the subsequent period by calculating the transition path from the state in 1996.06 to the new steady state obtained assuming that $\nu_{t}$ is constant and equal to $\nu_{1996.06}$. We keep repeating this procedure until 2010.12 under the assumption that each change in $\nu_{t}$ is treated as an unanticipated, permanent shock by households and firms who subsequently solve for their optimal policy functions. ${ }^{30}$

The sectoral labor flows and aggregate unemployment rate depend on the reallocation cost between sectors. We adopt the functional form $\Phi(i)=\left(\phi_{0} / \phi_{1}\right) i^{\phi_{1}}$. The parameter values $\phi_{0}$ and $\phi_{1}$ are calibrated to minimize the mean-squared distance between the model-implied paths for retail and construction labor with their U.S. data counterparts. We find that $\phi_{0}=2.1275$ and $\phi_{1}=1.4781$ provide the closest fit.

Figure 6 plots the results. The solid lines in each plot correspond to the model-implied data and the dashed lines are U.S. data. The increase in $\nu$ over the period 1996-2003 leads to a $3.5 \%$ increase in house prices followed by a relatively steep decline that brings house prices $4.5 \%$ below their 1996 value. ${ }^{31}$ While the path for house prices generated by the calibrated model is qualitatively consistent with the data - an increase in prices followed by a sharp decline - the model is unable to replicate the magnitude of these changes - the $60 \%$ increase to peak house prices in the data dwarfs the $3.5 \%$ increase from the model.

The second row in Figure 6 shows the sectoral labor shares. The left panel plots the fraction of the population employed in the general (nonconstruction) sector, and the right panel plots the fraction of the population employed in the construction sector. The data show an initial increase in the general sector employment and an increase in construction employment. Over the sample, the employment share in the general sector decreased while it increased in the construction sector until 2007 before dropping below its 1996 share. The model captures an initial increase in the employment shares in the goods sector followed by a decreasing share - though the experiment under consideration does not account for the 2001 recession. The model also reproduces the general features of construction employment with a roughly $0.75 \%$ drop in the construction share of employment over the whole period, though not quite matching the initial pace of labor flows. The aggregate unemployment rate, plotted in the upper right panel, is constructed as $1-n^{g}-n^{h}$. In particular, the collapse in house prices coincides with a sizable increase in the unemployment rate, though well below the peak rate in the data.

The bottom right panel plots the endogenous firm revenues, $z^{\chi}$, by sector. The relaxing of financial

\footnotetext{
${ }^{30}$ We also computed the perfect foresight path under the assumptions that agents know $\left\{\nu_{t}\right\}$. The results presented below are robust to this alternative approach. The dynamics are qualitatively similar but we find calibrating the values for $\phi_{0}, \phi_{1}$ to be computationally burdensome. Moreover, we prefer to interpret these financial innovations as permanent, unanticipated structural shocks to the economic environment.

${ }^{31}$ In contrast, the steady-state price sequence corresponding to the various values of $\nu$ feature a roughly $2 \%$ peak appreciation rate.
} 

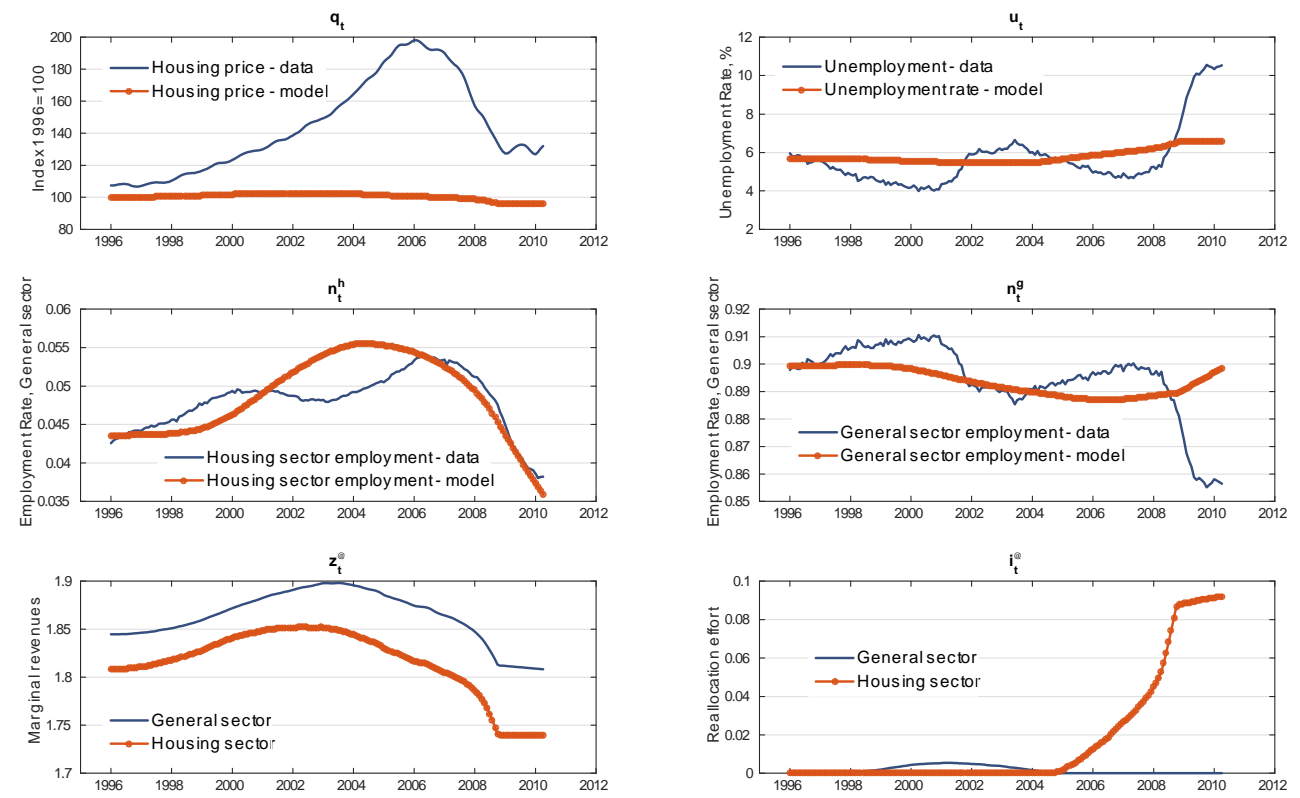

Figure 6: Dynamics under perfect foresight

constraints leads to a modest increase in house prices in the model, which raises the productivities in both sectors as well as the relative productivity of the construction sector. As a result, workers are better off in the construction sector, which leads to a worker flow from the general sector to the construction sector, as illustrated in the bottom left panel by the plain line that plots $i^{g}$. When financial constraints tighten again, the flow is reversed, as indicated by the dashed line that plots $i^{h}$.

\subsection{Adaptive learning}

The results from the experiment reported in Figure 6 demonstrate that the model under perfect foresight is able to replicate broad qualitative features of the U.S. housing and labor market data over the period 19962010. However, the quantitative predictions of the model, especially regarding house prices, are inconsistent with the data. This inability to explain the recent path for house prices appears to be a common feature of models with rational expectations. Hence, this section relaxes the perfect foresight assumption and replaces it with an adaptive learning rule that is in the spirit of Marcet and Sargent (1989) and Evans and Honkapohja (2001), among many others. ${ }^{32}$ In asset pricing applications, adaptive learning can lead to greater volatility in

\footnotetext{
${ }^{32}$ Adaptive learning theory is motivated by the strong cognitive and informational demands placed on agents in order for them to form rational expectations or, in the present environment, perfect foresight. In the long-run, rational expectations is a reasonable benchmark. However, along a transition path it seems implausible that households and firms have perfect foresight about endogenous state variables that are treated as exogenous in their own decision making. As an alternative, the literature adheres to a cognitive consistency principle that states that agents in the economy should forecast like a good
} 
response to economic shocks because these models are self-referential and impart a key role to forward-looking expectations.

To make decisions, households and firms must form expectations about house prices, $q_{t+1}$, sector-specific market tightness, $\theta_{t+1}^{\chi}$, and the value of intersector mobility $\triangle U_{t+1}$. Regarding the last two variables, $\theta^{\chi}$ and $\triangle U$, we assume a simple model of learning that preserves many of the features of rational expectations: agents in the economy know the new steady-state values for the variables of economic interest but are uncertain about the transition path. These assumptions lead us to propose a simple "anchoring and adjustment" rule of the form identified by Hommes (2013). Letting $x_{t+1}^{e}$ denote forecasts of the next period value of a state variable $x_{t}$, the forecast rule is as follows,

$$
\begin{aligned}
x_{t+1}^{e} & =\bar{x}+\gamma_{x} g_{t-1}^{x}\left(x_{t-1}-\bar{x}\right) \\
g_{t}^{x} & =g_{t-1}^{x}+\gamma_{g}\left(\frac{x_{t}}{x_{t-1}}-g_{t-1}^{x}\right),
\end{aligned}
$$

where $\bar{x}$ is the steady-state value of the state $x, g_{t}^{x}$ is a measure of the gross-growth rate of $x$ at time $t$ (details to be specified below), and $\gamma_{x} \geq 0$. The anchoring-and-adjustment learning rule, (50), has two components. The first component, the "anchor," is the new steady-state value of the variable, $x_{t}$, given $\nu_{t}$. Hence, agents are quite sophisticated in that they know the long-run fundamental value of the variable they are forecasting but are uncertain about its transition path. The second component in (50) is a persistent, or trend-following component according to which beliefs extrapolate based on deviations from steady state at a rate depending on the slope of the transition path, $g^{x} \cdot{ }^{33}$ The adaptive learning rule for the gross growth rate of $x, g^{x}$, is given by (51). The parameter $\gamma_{g}$ is called a "gain" coefficient as it parameterizes how strongly the learning rule discounts past data in estimating $g^{x}$.

Regarding the forecasting model for house prices we need a learning rule able to generate a large house price appreciation followed by a crash. To capture this feature of the data, we extend the learning model to incorporate strongly extrapolative house-price expectations:

$$
q_{t+1}^{e}=\gamma_{1} g_{t-1}^{q} q_{t-1}
$$

In (52), agents forecast house prices as the growth rate times the most recent data point with an extrapolating coefficient $\gamma_{1}$, where the estimate for the gross growth rate, $g^{q}$, is given by (51). When $\gamma_{1}=1$, this rule

econometrician, or Bayesian, by specifying a forecasting model and revising their specification in light of recent data. Typically, these forecasting models are econometric forecasting equations whose parameters are updated using a version of ordinary or discounted least-squares.

${ }^{33}$ It is worth noticing that the learning rule (50) nests rational expectations in a steady state, thus asymptotically these beliefs converge to their rational expectations values. 
nests the rational expectations equilibrium. ${ }^{34}$ In our calibration exercise, we allow for $\gamma_{1} \geq 1$, which can be justified in two ways. First, we interpret (52) as an approximation to a fully specified learning rule that might arise for a finite stretch of time in a stochastic model where $\gamma_{1}$ is estimated over time via discounted least-squares in an $\mathrm{AR}(1)$ regression of the growth rate. The approximate learning rule (52) implies that a self-fulfilling drift can arise that leads agents to perceive a trend in house prices. ${ }^{35}$ Second, we restrict $\gamma_{1}$ so that in the steady state agents' forecast errors are small, on the order of $0.2 \%$ in the calibration exercise.

In the calibration exercise, we select $\gamma_{1}, \gamma_{\theta}, \gamma_{\triangle U}, \phi_{1}$ to minimize the mean-squared distance between model-implied paths for $q_{t}, n_{t}^{g}, n_{t}^{h}, u_{t}$, and their counterparts in the data. To avoid overfitting, we impose that $\phi_{0}=1, \gamma_{g}=\gamma_{\triangle U}$. We find that the best fitting parameters are $\phi_{1}=1.295, \gamma_{\triangle U}=0.16, \gamma_{1}=1.0025$, and $\gamma_{\theta}=1.2$. The values for the learning-rule parameters lead to a stable steady state, i.e., the learning economy converges to the steady state. Figure 7 plots the equilibrium dynamics under learning. ${ }^{36}$

As before, the solid lines are the equilibrium paths and the dashed lines are the corresponding data series. Under learning house prices in the model capture the peak house price appreciation in the data. The magnitude of the drop in prices from 2005-2010 is in line with data.The improved fit in house prices leads to a much improved fit in construction employment shares. Revenues in the construction sector (bottom right panel) increase significantly from 1996-2005, which leads to an increase in employment and labor mobility from the general to the construction sector. Employment in the construction sector broadly follows the same increase as the one observed in the data over this period, about one percentage point. From 2006-2010, the data and the model feature an even greater drop in construction employment. The model also captures the trend in nonconstruction employment. The initial increase in the general sector productivity, $z^{g}$, that arises from the increased $\nu$ leads to a strong increase in $n^{g}$. However, the strong house price appreciation eventually leads to a relative increase in the share of construction sector employment, $n^{h} /\left(n^{h}+n^{g}\right)$, and a reallocation of workers toward the construction sector. Moreover, as the housing boom crashes, so does

\footnotetext{
${ }^{34}$ This rule is of the same form as the one used by Adam, Marcet and Nicolini (2013) to study asset pricing under learning.

${ }^{35}$ Learning dynamics with self-fulfilling volatility are a general feature of learning models along the lines described above in a wide class of forward-looking stochastic models. Branch (2014) studies a stochastic search-based asset pricing model with a pricing equation very similar to the house price equation in this paper and where rational expectations replaced by an AR(1) econometric learning rule. The parameters of this learning rule are updated using discounted least-squares. He shows that bubbles can arise from an overshooting effect from structural changes to the asset's liquidity, such as its acceptability $\nu$. These bubbles arise as beliefs endogenously evolve to perceive the asset price as following a random walk without drift - in this case, recent price innovations are temporarily perceived to be permanent leading to an overshooting of the new fundamental price that will eventually collapse and return to its fundamental value. Thus, the learning rule (52) captures in a nonstochastic environment this general feature in learning models (See Sargent, 1999).

${ }^{36}$ We checked for robustness across a wide range of learning model specifications, including a model where all expectations are of the form (50), a model without the growth rate terms, "constant gain" algorithms that take a geometric average of past data, and even learning models that include contemporaneous endogenous variables in the forecasts. Across all of these specifications there is a consistent set of quantitative results: house prices increase modestly, goods sector employment matches up well with the data, and there is a slight increase in construction sector employment share. The key to a good empirical fit is a model of expectation formation that leads to a housing price boom, such as (52).
} 

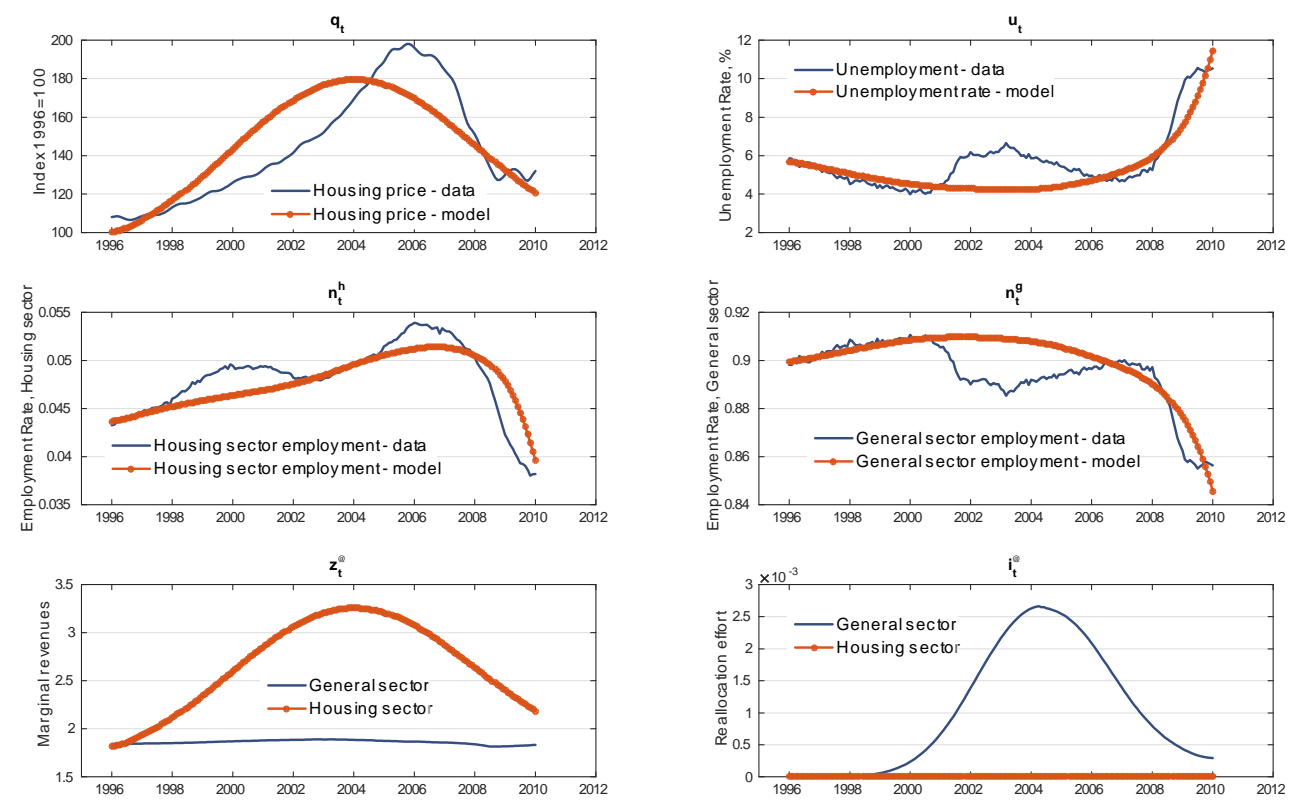

Figure 7: Equilibrium dynamics under learning

employment in the non-construction goods sector.

The lower right panel plots the model implied unemployment against actual U.S. unemployment rate (dashed line). The aggregate unemployment rate in the model declines about 1.5\% from 1996 to 2005 and it increases above $10 \%$ in 2010 , which is consistent with the data. Not surprisingly, the model misses the fluctuations of the unemployment rate following the 2001 recession. Since the housing market was insulated from this recession there is no mechanism in the model that can capture the changes in unemployment over that period.

\section{Conclusion}

We have studied the effects of changes in household finance on the labor and housing markets. We have constructed a tractable general equilibrium model that generalizes the Mortensen-Pissarides framework along several dimensions: The labor market has two sectors, including a construction sector. There is a frictional goods market, where household consumption is financed with collateralized or unsecured loans. There is a housing market where households can rent housing services and buy and sell homes. The model has generated a variety of new insights - e.g., how financial frictions and liquidity constraints provide new linkages between goods, housing, and labor markets - and it has been used to study analytically how changes in households' 
eligibility for home equity loans affect the dynamics of house prices and aggregate unemployment.

We calibrated the model to the U.S. economy and showed that it could capture salient features of U.S. housing and labor market data, including: a sustained increase, followed by sharp decrease, in home equity financed consumption; a large house price boom/crash; a sustained decrease in the aggregate unemployment rate during the house price boom followed by a sharp increase in the unemployment rate as house prices collapse; and a sizable increase in the share of employment in the construction sector during the house price boom. Figure 6 obtained under perfect foresight captures these empirical regularities and the learning version, Figure 7, provides a good quantitative fit. Therefore, the model presented here, with explicit a housing market, labor and goods market with explicit frictions, can capture many of the salient features of housing prices, unemployment, and sectoral labor flows. 


\section{References}

[1] Abdallah, Chadi, and William Lastrapes (2012). "Home equity lending and retail spending: Evidence from a natural experiment in Texas," American Economic Journal: Macroeconomics 4, 94-125.

[2] Adam, Klaus, Albert Marcet and Juan-Pablo Nicolini (2013). "Stock Market Volatility and Learning," working paper.

[3] Adelino, Manuel, Antoinette Schoar and Felipe Severino (2012). "Credit supply and house prices: Evidence from mortgage market segmentation," Mineo, Duque University.

[4] Aruoba, Boragan, Guillaume Rocheteau and Christopher Waller (2007). "Bargaining and the value of money," Journal of Monetary Economics 54, 2636-2655.

[5] Berentsen, Aleksander, Guido Menzio and Randall Wright (2011). "Inflation and unemployment in the long run," American Economic Review, 101, 371-98.

[6] Bethune, Zach, Guillaume Rocheteau, and Peter Rupert (2013). "Unemployment and household unsecured debt," Working Paper, University of California, Irvine.

[7] Branch, William A. and George W. Evans (2011). "Learning about Risk and Return: A Simple Model of Bubbles and Crashes," American Economic Journal: Macroeconomics, 3, 159-191.

[8] Branch, William A. (2014). "Imperfect Knowledge, Liquidity and Bubbles," working paper.

[9] Byun, Kathryn (2010). "The U.S. housing bubble and bust: impacts on employment," Bureau of Labor and Statistics Monthly Review (December), 3-17.

[10] Campbell, John, and Joao Cocco (2007). "How do house prices affect consumption? Evidence from micro data," Journal of Monetary Economics 54, 591-621.

[11] Chang, Briana (2012). "A search theory of sectoral reallocation," Working Paper.

[12] Davis, Steven, Jason Faberman and John Haltiwanger (2010). "The establishment-level behavior of vacancies and hiring," NBER working Paper No. 16265.

[13] Den Haan, Wouter, Garey Ramey, and Joel Watson (2000). "Job destruction and propagation of shocks," American Economic Review 90, 482-498. 
[14] Ducca, John, John Muellbauer and Anthony Murphy (2011). " House prices and credit constraints: making sense of the US experience," Economic Journal 121, 533-551.

[15] Dugan, John (2008). "Rising losses in home equity lending," Remarks by the Comptroller of the Currency Before the Housing Policy Council of the Financial Services Roundtable, May 22, 2008. Available at: http://www.occ.gov/news-issuances/speeches/2008/pub-speech-2008-58.pdf

[16] Evans, George W., and Seppo Honkapohja (2001). Learning and Expectations in Macroeconomics. Princeton, NJ: Princeton University Press.

[17] Evans, George W., and Bruce McGough (2014). "Learning to Optimize," working paper.

[18] Ferraris, Leo, and Makoto Watanabe (2008). "Collateral secured loans in a monetary economy," Journal of Economic Theory 143, 405-424.

[19] Garriga, Carlos, Rodolfo Manuelli, and Adrian Peralta-Alva (2012). "A model of price swings in the housing market," Federal Reserve Bank of St Louis Working Paper 2012-022A.

[20] Geromichalos, A., J. M. Licari and J. Suarez-Lledo (2007). "Monetary policy and asset prices," Review of Economic Dynamics 10, 761-779.

[21] Gomme, Paul, and Peter Rupert (2007). "Theory, measurement and calibration of macroeconomic models". Journal of Monetary Economics 54, 460-497.

[22] Greenspan, Alan, and James Kennedy (2007). "Sources and uses of equity extracted from homes," Staff Working Papers in the Finance and Economics Discussion Series of the Federal Reserve Board 2007-20.

[23] Harding, John, Stuart Rosenthal, and C.F. Sirmans (2007). "Depreciation of housing capital, maintenance, and house price inflation: Estimates from a repeat sales model," Journal of Urban Economics $61,193-217$.

[24] He, Chao, Randall Wright, and Yu Zhu (2013). "Housing and liquidity," Working Paper of the University of Wisconsin.

[25] Head, Allen and Huw Lloyd-Ellis (2011). "Housing liquidity, mobility, and the labour market," Review of Economic Studies (Forthcoming).

[26] Hommes, Cars (2013). Behavioral Rationality and Heterogeneous Expectations in Complex Economic Systems. Cambridge, UK: Cambridge University Press. 
[27] Iacoviello, Matteo (2011). "Housing wealth and consumption," International Encyclopedia of Housing and Home, Elsevier.

[28] Karahan, Fatih, and Serena Rhee (2012). "Housing and the labor market: The role of migration on aggregate unemployment," Working Paper.

[29] Kiyotaki, Nobuhiro, and John Moore (1997). "Credit cycles," Journal of Political Economy 105, 211-248.

[30] Kiyotaki, Nobuhiro, and John Moore (2005). "Liquidity and asset prices," International Economic Review 46, 317-349.

[31] Lagos, Ricardo (2010). "Asset prices and liquidity in an exchange economy," Journal of Monetary Economics 57, 913-30.

[32] Lagos, Ricardo (2011). "Asset prices, liquidity, and monetary policy in an exchange economy," Journal of Money, Credit, and Banking 43, 521-552.

[33] Lagos, Ricardo and Randall Wright (2005). "A unified framework for monetary theory and policy analysis," Journal of Political Economy 113, 463-484.

[34] Lester, Ben, Postlewaite, Andrew, Wright, Randall (2012). "Information, liquidity, asset prices and monetary policy," Review of Economic Studies 79, 1209-1238.

[35] Li, Ying-Syuan and Li, Yiting, 2013. "Liquidity and asset prices: A new monetarist approach," Journal of Monetary Economics 60, 426-438.

[36] Li, Yiting, Guillaume Rocheteau, and Pierre-Olivier Weill (2012). "Liquidity and the threat of fraudulent assets," Journal of Political Economy 120, 815-846.

[37] Lucas, Robert, and Prescott, Ed (1974). "Equilibrium search and unemployment," Journal of Economic Theory 7, 188-209.

[38] Mankiw, Gregory and David Weil (1989). "The baby boom, the baby bust, and the housing market," Regional Science and Urban Economics 19, 235-258.

[39] Marcet, Albert and Thomas J. Sargent (1989). "Convergence of Least-Squares Learning Mechanisms in Self-Referential Models," Journal of Economic Theory, 48, 337-368. 
[40] Mian, Atif, and Amir Sufi (2009). "House prices, home equity-based borrowing, and the U.S. household leverage crisis," NBER Working Paper 15283.

[41] Mian, Atif, and Amir Sufi (2012). "What explains high unemployment? The aggregate demand channel," NBER Working Paper 17830.

[42] Mian, Atif, and Amir Sufi (2014a). House of Debt. Chicago, IL: University of Chicago Press.

[43] Mian, Atif, and Amir Sufi (2014b). "House Price Gains and U.S. Household Spending from 2002 to 2006," working paper.

[44] Midrigan, Virgiliu and Thomas Philippon (2011). "Household leverage and the recession," Working Paper.

[45] Mortensen, Dale, and Christopher Pissarides (1994). "Job creation and job destruction in the theory of unemployment," The Review of Economic Studies 61, 397-415.

[46] Mulligan, Casey (2012). "Do welfare policies matter for labor market aggregates? Quantifying safety net work incentives since 2007," NBER working paper 18088.

[47] Petrosky-Nadeau, Nicolas (2013). "TFP During a Credit Crunch," Journal of Economic Theory, 148,3, $1150-1178$.

[48] Petrosky-Nadeau, Nicolas, and Etienne Wasmer (2011). "Macroeconomic dynamics in a model of goods, labor and credit market frictions," mimeo, Carnegie Mellon University.

[49] Petrongolo, Barbara and Pissarides, Christopher A. (2001). "Looking into the black box: A survey of the matching function," Journal of Economic Literature 39, 390-431.

[50] Petrosky-Nadeau, Nicolas, and Etienne Wasmer (2012). "The cyclical volatility of labor markets under frictional financial markets," American Economics Journal: Macroeconomics, forthcoming.

[51] Phelan, Christopher, and Alberto Trejos (2000). "The aggregate effects of sectoral reallocations," Journal of Monetary Economics 45, 249-268.

[52] Pissarides, Christopher (2000). Equilibrium Unemployment Theory. (Second Ed.). Cambridge, MA: MIT Press. 
[53] Rocheteau, Guillaume (2011). "Payments and liquidity under adverse selection," Journal of Monetary Economics 58, 191-205.

[54] Rocheteau, Guillaume, Peter Rupert and Randall Wright (2007). "Inflation and unemployment in general equilibrium," Scandavian Journal of Economics 109, 837-855.

[55] Rocheteau, Guillaume and Randall Wright (2005). "Money in search equilibrium, in competitive equilibrium, and in competitive search equilibrium," Econometrica 73, 175-202.

[56] Rocheteau, Guillaume and Randall Wright (2013). "Liquidity and asset-market dynamics," Journal of Monetary Economics 60, 275-294.

[57] Rosen, Harvey (1979). "Housing decisions and the US. income tax," Journal of Public Economics 11, $1-23$.

[58] Rudanko, Leena (2011). "Aggregate and idiosyncratic risk in a frictional labor market," American Economic Review 101, 2823-2843.

[59] Rupert, Peter, and Etienne Wasmer (2012). "Housing and the labor market: Time to move and aggregate unemployment," Journal of Monetary Economics 59, 24-36.

[60] Sargent, Thomas J. (1999). The Conquest of American Inflation. Princeton, NJ: Princeton University Press.

[61] Shi, Shouyong (1998). "Search for a monetary propagation mechanism," Journal of Economic Theory $81,314-352$.

[62] Telyukova, Irina and Randall Wright (2008). "A model of money and credit, with application to the credit card debt puzzle," Review of Economic Studies 75, 629-647.

[63] Timmermann, Allan (1994). "Excess Volatility and Predictability of Stock Returns in Autoregressive Dividend Models with Learning," Review of Economic Studies, 523-447.

[64] Wasmer, Etienne, and Philippe Weil (2004). "The macroeconomics of labor and credit market imperfections," American Economic Review 94, 944-963. 


\section{Appendix: Proofs of propositions}

Proof of Proposition 1. As it has been shown in the text Condition (38) guarantees the existence of an equilibrium with two active markets. Market tightness, $\theta$, is the unique solution to (37). The left side of (37) is increasing in $\theta$ and the right side is increasing in $\bar{z}^{g}$. Therefore, $\partial \theta / \partial \bar{z}^{g}>0$. By a similar reasoning one obtains the comparative statics for $\theta$ in the second row of the table. The unemployment rate is $u=$ $\sigma /[m(1, \theta)+\sigma]$. The comparative statics for $u$ are obtained from the comparative statics for $\theta$. For instance, since $u$ is decreasing in $\theta, \partial u / \partial \bar{z}^{g}<0$. Employment in the housing sector is $n^{h}=\delta \vartheta^{\prime-1}\left[(r+\delta) \bar{z}^{g} / \bar{z}^{h}\right] / \bar{z}^{h}$. Since $\vartheta^{\prime}$ is decreasing it follows that $\partial n^{h} / \partial \bar{z}^{g}<0$. Moreover, differentiating $\vartheta^{\prime}\left(n^{h} \bar{z}^{h} / \delta\right)=(r+\delta) \bar{z}^{g} / \bar{z}^{h}$ and using that $\bar{z}^{h} n^{h} / \delta=A$, we obtain the following elasticity:

$$
\frac{\partial n^{h} / n^{h}}{\partial \bar{z}^{h} / \bar{z}^{h}}=\frac{-\vartheta^{\prime}(A)}{A \vartheta^{\prime \prime}(A)}-1
$$

So $\partial n^{h} / \partial \bar{z}^{h}>0$ if $\left|\vartheta^{\prime}(A) / A \vartheta^{\prime \prime}(A)\right|>1$. An increase in the marginal utility of housing services, $\vartheta^{\prime}$, leads to an increase in $n^{h}$. Employment in the consumption goods sector is determined by $n^{g}=1-u-n^{h}$. Therefore, $\partial n^{g} / \partial \bar{z}^{g}=-\partial u / \partial \bar{z}^{g}-\partial n^{h} / \partial \bar{z}^{g}>0$. The rest of the comparative statics for $n^{g}$ follow a same logic. The stock of housing is given by $A=\vartheta^{\prime-1}\left[(r+\delta) \bar{z}^{g} / \bar{z}^{h}\right]$. Since $\vartheta^{\prime}$ is decreasing, $\partial A / \partial \bar{z}^{g}<0$ and $\partial A / \partial \bar{z}^{h}>0$. An increase in the marginal utility for housing services increases the supply of homes. Finally, house prices are $q=\bar{z}^{g} / \bar{z}^{h}$ so that $\partial q / \partial \bar{z}^{g}>0$ and $\partial q / \partial \bar{z}^{h}<0$.

Proof of Proposition 2. The statements in the proposition are proven in the text. In the following we explain how we obtained the comparative statics for the case where liquidity is scarce, $\vartheta^{\prime}(A) A<$ $r \mu b\left(y^{*}\right) /(1+r) \rho$. The pair of endogenous variables, $(q, \theta)$, is jointly determined by (39) and (41). Both equations give a positive relationship between $\theta$ and $q$. Since the equilibrium might not be unique, we focus on equilibria where the $H P$ curve - representing (41)- intersects the $J C$ curve - representing (39)- from below, in the space $(q, \theta)$. From (39), given $q$ an increase in $\bar{z}$ or $\nu$ raises $\theta$. Graphically $J C$ moves upward. From (41), given $\theta$ an increase in $\bar{z}$ or $\nu$ does not affect $q$. Graphically, $H P$ does not shift. It follows that the equilibrium values of $\theta$ and $q$ increase. By a similar reasoning, an increase in $\lambda, w_{0}, \sigma$, or $k$ moves $J C$ downward without affecting $H P$. Therefore, $\theta$ and $q$ decrease. We show in the text that an increase in $\mu$ shifts $J C$ upward. From (41) an increase in $\mu$ reduces the stock of housing of homeowners, $A / \mu$, which reduces $y$ and increases the liquidity premium on housing for a given $\theta$. Therefore, $H P$ moves to the right. The overall effect is an increase in both $\theta$ and $q$. An increase in $\rho$ raises market tightness given by (39) for a given $q$. So $H P$ moves upward. The effect on house prices given by (41) is ambiguous. Finally, given $\theta$ the 
unemployment rate is determined by $u=\sigma /[m(1, \theta)+\sigma]$.

Derivation of the wage equation (21) The firm's surplus, $J^{\chi}$, is given by (18). From (8), (14), and (15) the value of an employed household holding its optimal level of liquid assets solves

$$
V_{1, t}^{\chi}=w_{1, t}^{\chi}+\varpi_{t}+\beta\left[\left(1-\sigma^{\chi}\right) V_{1, t+1}^{\chi}+\sigma^{\chi} V_{0, t+1}^{\chi}\right], \quad \chi \in\{h, g\},
$$

where

$$
\varpi_{t}=\mathbb{E}\left[v\left(y_{t}\right)-y_{t}\right]+\left[q_{t}(1-\delta)+R_{t}\right] a_{t}-q_{t} a_{t+1}+\max _{d_{t} \geq 0}\left\{\vartheta\left(d_{t}\right)-R_{t} d_{t}\right\}+\Delta_{t} .
$$

From the first two terms on the right side of (53) the period- $t$ utility of an employed household is the sum of the wage paid by the firm, the expected surplus in the DM goods market, the return on its real estate net of depreciation, the utility of housing services net of the rental cost, and firms' profits. The third term on the right side of (53) describes the transitions in the next LM. With probability $1-\sigma^{\chi}$ the household remains employed in the following period and enjoys the discounted utility $\beta V_{1, t+1}^{\chi}$; with complement probability, $\sigma^{\chi}$, the household loses its job and its discounted utility is $\beta V_{0, t+1}^{\chi}$. Substract $V_{0, t}^{\chi}$ on both sides to obtain the surplus of an employed worker,

$$
V_{1, t}^{\chi}-V_{0, t}^{\chi}=w_{1, t}^{\chi}+\varpi_{t}+\beta\left[\left(1-\sigma^{\chi}\right) V_{1, t+1}^{\chi}+\sigma^{\chi} V_{0, t+1}^{\chi}\right]-V_{0, t}^{\chi}
$$

From (18) and (55) the total surplus of a match, $\mathbb{S}_{t}^{\chi} \equiv V_{1, t}^{\chi}-V_{0, t}^{\chi}+J_{t}^{\chi}$, solves the following recursion:

$$
\mathbb{S}_{t}^{\chi}=z_{t}^{\chi}+\varpi_{t}-V_{0, t}^{\chi}+\beta V_{0, t+1}^{\chi}+\beta\left(1-\sigma^{\chi}\right) \mathbb{S}_{t+1}^{\chi}
$$

From the bargaining solution, $V_{1, t}^{\chi}-V_{0, t}^{\chi}=\lambda^{\chi} \mathbb{S}_{t}^{\chi}$, which from (55) and (56) gives the following expression for the wage:

$$
w_{1, t}^{\chi}=\lambda^{\chi} z_{t}^{\chi}+\left(1-\lambda^{\chi}\right)\left(V_{0, t}^{\chi}-\beta V_{0, t+1}^{\chi}-\varpi_{t}\right) .
$$

The wage is a weighted average of the firm's expected revenue, $z_{t}^{\chi}$, and the worker's reservation wage is defined as $V_{0, t}^{\chi}-\beta V_{0, t+1}^{\chi}-\varpi_{t}$.

Using the same reasoning as above, the expected discounted utility of an unemployed household at the beginning of the LM is

$$
V_{0, t}^{\chi}=w_{0}^{\chi}+\varpi_{t}+\beta\left[V_{0, t+1}^{\chi}+p_{t+1}^{\chi}\left(V_{1, t+1}^{\chi}-V_{0, t+1}^{\chi}\right)\right]+\Omega\left(i_{t+1}^{\chi}\right) .
$$

The third term on the right side of (58) is the household continuation value if it does not relocate to a new sector. The last term on the right side of (58) captures the net expected gain that a household enjoys 
from moving to a different sector. From the bargaining solution, $V_{1, t}^{\chi}-V_{0, t}^{\chi}=\frac{\lambda^{\chi}}{1-\lambda \chi} J_{t}^{\chi}$; from free entry, $J_{t}^{\chi}=k^{\chi} / \beta f_{t}^{\chi}$. Therefore, from (58), the value of an unemployed household can be expressed as

$$
V_{0, t}^{\chi}=\beta V_{0, t+1}^{\chi}+w_{0}^{\chi}+\varpi_{t}+\frac{\lambda^{\chi}}{1-\lambda^{\chi}} \theta_{t+1}^{\chi} k^{\chi}+\Omega\left(i_{t+1}^{\chi}\right)
$$

Substitute $V_{0, t}^{\chi}-\beta V_{0, t+1}^{\chi}$ from (59) into (57) to obtain (21).

Sectoral reallocation: Derivation of Equation (22) From the Bellman equation, $U_{0, t}^{\chi}\left(a_{t}\right)=p_{t}^{\chi} V_{1, t}^{\chi}\left(a_{t}\right)+$ $\left(1-p_{t}^{\chi}\right) V_{0, t}^{\chi}\left(a_{t}\right)$, and the surplus sharing rule, $\beta p_{t}^{\chi}\left(V_{1, t}^{\chi}-V_{0, t}^{\chi}\right)=\lambda^{\chi} \theta_{t}^{\chi} k^{\chi} /\left(1-\lambda^{\chi}\right)$, the gain from moving to a different sector, $\Delta U_{t}^{\chi} \equiv \beta\left(U_{0, t}^{\chi^{\prime}}-U_{0, t}^{\chi}\right)$, can be expressed as

$$
\Delta U_{t}^{\chi}=\beta\left(V_{0, t}^{\chi^{\prime}}-V_{0, t}^{\chi}\right)+\frac{\lambda^{\chi^{\prime}}}{1-\lambda^{\chi^{\prime}}} \theta_{t}^{\chi^{\prime}} k^{\chi^{\prime}}-\frac{\lambda^{\chi}}{1-\lambda^{\chi}} \theta_{t}^{\chi} k^{\chi}
$$

This is equal to the surplus an unemployed worker would enjoy in the DM from being in a different sector augmented by a term proportional to the difference of average recruiting costs across sectors. Using the fact that $V_{0, t}^{\chi}=w_{0}^{\chi}+\varpi_{t}+\beta U_{0, t+1}^{\chi}+\Omega\left(i_{t+1}^{\chi}\right)$, one obtains $(22)$. 


\section{For Online Publication}

\section{A Data Appendix}

The data used in calibrating the model are the following:

Job destruction rates: Total Separation - Non-Farm; FRED II I.D. JTSTSR. Total Separation - Construction; FRED II I.D. JTU2300TSR

Employment: All Employees - Total Non-Farml; FRED II I.D. PAYEMS. All Employees - Constructions; FRED II I.D. USCONS

Unemployment: Aggregate Unemployment: UNEMPLOY. Construction Unemployment; FRED II I.D. LNU03032231.

Housing Stock and GPD: Real Estate Assets, Balance Sheet of Households and Non-Profit Organizations; FRED II I.D. REABSHNO. Gross Domestic Product; FRED II I.D. GDP.

Rent to Price Ratio: Lincoln Institute of Land Policy.

Equity Financed Consumption: Greenspan and Kennedy (2007). 


\section{Appendix: Model with Adaptive Learning}

This Appendix details the key equations in the model under adaptive learning. Households and firms are assumed to form forecasts, generated by learning rule (50), for payoff-relevant aggregate variables that are taken as exogenous when making their optimal decisions. As in the perfect foresight case, agents take the $\nu_{t}$ shock to be unanticipated and permanent. Given a $\nu_{t}$ they calculate the new steady state and, then, using the most recently observed data, form expectations about the next realization of the aggregate state variables $q_{t}, \theta_{t}^{g}, \theta_{t}^{h}, \triangle U_{t}$. Adaptive learning models are sometimes complicated by the evolving beliefs of optimizing agents and the literature differs on whether to treat the agents as fully Bayesian decision-makers that account for the future evolution of their beliefs when formulating their optimal plans. ${ }^{37}$ In the present environment, these issues are not directly relevant since the (temporary) equilibrium equations are nonstochastic and the quasi-linearity assumptions in the CM utility function eliminate wealth effects. Agents in this model are able to iterate their forecasts forward as the coefficients in the forecasting model are fixed. There are, however, two key behavioral assumptions that we impose on agents. First, households and firms form their forecasts after observing $\nu_{t}$ but before observing contemporaneous market-clearing state variables. This is a standard assumption in the literature and is designed to break the simultaneity between beliefs and outcomes that are natural in a rational expectations setting but implausible in a learning environment. Second, agents hold point expectations when satisfying their optimization conditions. Again, because of the nonstochastic nature of the model this assumption is natural.

The timing of the model is as follows. At the beginning of period $t$, a new unanticipated shock to $\nu_{t}$ occurs. Agents observe this, calculate the new steady state, and update their expectations conditional on observing data that were realized at the end of the CM in $t-1$, i.e. $q_{t-1}, \triangle U_{t-1}$. Subsequently, the LM opens with firms choosing to post vacancies given their expectations about trade in the DM in period $t$, as well as the vacancy rate in $t+1$. The pool of unemployed workers in each sector depends on the previous pool of unemployed and the aggregate mobility decisions of agents that were made at the end of period $t-1$. These decisions depend on the expected value of mobility, $\triangle U_{t}$, that are made conditional on data through the end of $t-1$. The labor market clears and $\theta_{t}$ is realized. Agents subsequently revise their expectations about $\theta_{t+1}$ given this new data point. The DM then opens, firms and households are matched, and they bargain given their expectations. After the DM closes, the CM opens and households payoff their debts from

\footnotetext{
${ }^{37}$ See Evans and McGough (2014) for discussion of various decision theoretic issues in boundedly rational macroeconomic models.
} 
the DM, are paid their wages from work in the LM, accumulated inventories from the DM are sold, and households decide on their housing purchases and housing services consumption, all given their expectations. The housing, numeraire, and rental markets clear, and there is a realization of the intersector mobility value $\triangle U_{t}$. Unemployed workers then decide on their reallocation intensity for the next period.

The (temporary) equilibrium equations for the aggregate variables are as follows (denoting $x^{e}$ as the expected value of variable $x$ ):

$$
\begin{aligned}
\theta_{\chi t} & =\left\{\frac{\kappa_{\chi}}{\beta m_{\chi}\left[\left(1-\lambda_{\chi}\right)\left(z_{\chi t}^{e}-w_{0 \chi}-\Omega_{\chi t}^{e}\right)-\lambda_{\chi} \kappa_{\chi} \theta_{\chi t+1}^{e}+\left(1-\sigma^{\chi}\right) \kappa_{\chi} /\left(m_{\chi} \theta_{\chi t+1}^{e}\right)^{-\varepsilon_{\chi}}\right]}\right\}^{-1 / \varepsilon_{\chi}} \\
q_{t} & =\frac{1}{1+r}\left[(1-\delta) q_{t+1}^{e}+R_{t+1}\right]\left(1+L_{t+1}^{e}\right) \\
\Delta U_{t} & =\beta\left(w_{0 h}-w_{0 g}+\Omega_{g t+1}^{e}-\Omega_{h t+1}^{e}\right)+\beta \triangle U_{t+1}^{e}+\frac{\lambda_{h}}{1-\lambda_{h}} \kappa_{h} \theta_{h t}-\frac{\lambda_{g}}{1-\lambda_{g}} \kappa_{g} \theta_{g t}
\end{aligned}
$$

Note that $R_{t+1}$ depends on $A_{t+1}$ which is known in the CM of period $t$. These equations specify a set of nonlinear difference equations in the key endogenous state variables, and, when combined with the learning rules (50)-(52), determine the temporary equilibrium path for the endogenous state variables. 